\title{
Experimental and Numerical Studies on the Vertical Flow of Variable Density Fluid in Different Directions
}

\author{
Zhifang Zhou, ${ }^{1}$ Boran Zhang, ${ }^{1,2}$ Qiaona Guo $\mathbb{D}^{1}{ }^{1}$ and Shumei Zhu ${ }^{1}$ \\ ${ }^{1}$ School of Earth Sciences and Engineering, Hohai University, No. 8 Focheng West Road, Nanjing 211100, China \\ ${ }^{2}$ China Communication Planning and Design Institute for Waterway Transportation, Beijing, China \\ Correspondence should be addressed to Qiaona Guo; guoqiaona2010@hhu.edu.cn
}

Received 27 November 2018; Revised 16 February 2019; Accepted 11 March 2019; Published 24 April 2019

Academic Editor: Ye Zhang

Copyright (C) 2019 Zhifang Zhou et al. This is an open access article distributed under the Creative Commons Attribution License, which permits unrestricted use, distribution, and reproduction in any medium, provided the original work is properly cited.

\begin{abstract}
Injecting freshwater and pumping salt water are effective methods to restore the salt water in a coastal area. Based on a onedimensional vertical experiment, the variable density flow is simulated under the condition of different injection directions and injection rates of fresh water. A one-dimensional mathematical model of variable density flow and solute transport is established. The mathematical models are solved using the implicit difference method. Fortran code is developed to simulate and verify the vertical flow of variable density flow in different directions. Through both numerical simulation and experimental studies, it is found that the variable density fluid in the direction of reverse gravity is different from that in the direction of gravity. On this basis, the most effective desalination model of salt water is further discussed. It provides a theoretical and technical method for the restoration of salt water in the vertical injection of freshwater. In order to improve the remediation efficiency and reduce the cost in the engineering application, the suitable water injection rate should be ensured, considering the suitable construction time and zone of a study area.
\end{abstract}

\section{Introduction}

The law of fluid flow is different from that in the homogeneous fluid, when the fluid density in the flow field is uneven [1]. Fluid density is the mass of fluid in unit volume, which is related to the flow direction under the influence of gravity. Due to the uneven fluid density, the movement of groundwater is more closely related to the direction of fluid flow, especially in the vertical direction [2]. As it is known to us, the process of seawater intrusion or the inverse process (restoration of salt water) is a typical problem caused by variable density fluid flow.

It is a common phenomenon that seawater flows into the coastal aquifer as a result of the overexploitation of groundwater by humans in coastal areas, which occurs in densely populated coastal areas around the world, especially in China [3-7]. Take the Laizhou Bay, Shandong Province, as an example; the overexploitation has resulted in the problem of seawater intrusion since 1980s [8]. The area of the seawater intrusion has reached more than 970 square kilometers, which caused serious deterioration of a groundwater environment and imbalance of an ecosystem. Xue et al. [9] developed a three-dimensional numerical model to simulate seawater intrusion and brine water and freshwater interaction in the Longkou-Laizhou area. They studied the interface distribution between freshwater and saltwater and evolution of the transitional zone and evaluated seawater intrusion caused by groundwater pumping. In addition, the Jiaozhou Bay area is one of the most serious areas effected by seawater intrusion in China [6]. In order to prevent the seawater intrusion, the local government built an underground concrete cutoff wall, with the length of 4 kilometers and depth of 20 meters. It prevented further seawater intrusion, and good results have been achieved. However, there is still $15.67 \mathrm{~km}^{2}$ underground salt water reserving inside the cutoff walls, which affects the local industrial and domestic water demand seriously. Therefore, it is urgent to take further measures.

In view of the problem of controlling the salt water in a coastal aquifer, it is an effective method to remove the salt water by injecting freshwater, which has been widely studied and applied in the world. At present, the laboratory experiment and numerical simulation are the most 
common and useful methods to study the restoration of salt water. Abarca et al. [10] studied the optimal combination of different restoration methods and increased the reservation of underground freshwater resources in order to protect the freshwater resources from seawater intrusion. Bray and Yeh [11] used the numerical simulation method to minimize the amount of water injection for restoring salt water, considering the effects of groundwater head and concentration of salt water. Vandenbohede et al. [12] numerically analyzed the restoration of salt water in the Western Belgian aquifer by using MOCDENS3D code, with the method of increasing the efficiency of groundwater extraction and reducing the consumption of groundwater reserves. Recently, there are several researches carried out to arrange a row of pumping or injection wells along the coastline to discharge and recharge water in the field, as shown in Figure $1[13,14]$. The freshwater is injected in inland to repulse the saltwater wedge, while the saltwater is extracted near the shore to slow its encroachment. For example, Wei and Zheng [14] used the method of extracting salt water and injecting freshwater in the saline aquifer near Dagu River, Shandong Province, China. The results showed that salt water can be displaced by injecting freshwater and desalted at the same time which promotes saline groundwater recovery. However, this method would require significant operational and maintenance costs due to the high risk of clogging and reduction of a filtering area of the screen involved in the use of wells [15].

Up to now, the experiment on the restoration of underground salt water is mainly based on the method of injecting freshwater to restore the salt water in the horizontal direction [10-14]. Actually, there is a gravity difference between the freshwater and salt water due to the difference in density in the vertical direction. For example, Dejam and Hassanzadeh $[16,17]$ studied the diffusive leakage of brine from aquifers during the injection of $\mathrm{CO}_{2}$ in the geological storage. From our review of the literature, there is no study on the restoration of salt water and the effect of restoration in the vertical direction. The difference of saltwater restoration in different directions of water injection is not considered.

Based on the above review, this study is aimed at investigating the vertical flow of variable density fluid in different directions. Firstly, the experiments were conducted considering different water injection directions and water injection rates in the vertical direction. Then, based on the experimental simulation, the mathematical model of one dimensional variable density flow and solute transport was established, and the vertical flow of variable density fluid was further validated by numerical simulations. Subsequently, the most effective desalination model is discussed, which provides a theoretical and technical basis for the restoration of salt water by vertical injection of freshwater.

\section{Materials and Methods}

2.1. Experimental Setup. In order to study the vertical flow of variable density fluid in different directions and discuss the feasibility and efficiency of restoration of salt water, a onedimensional vertical model is established to simulate the

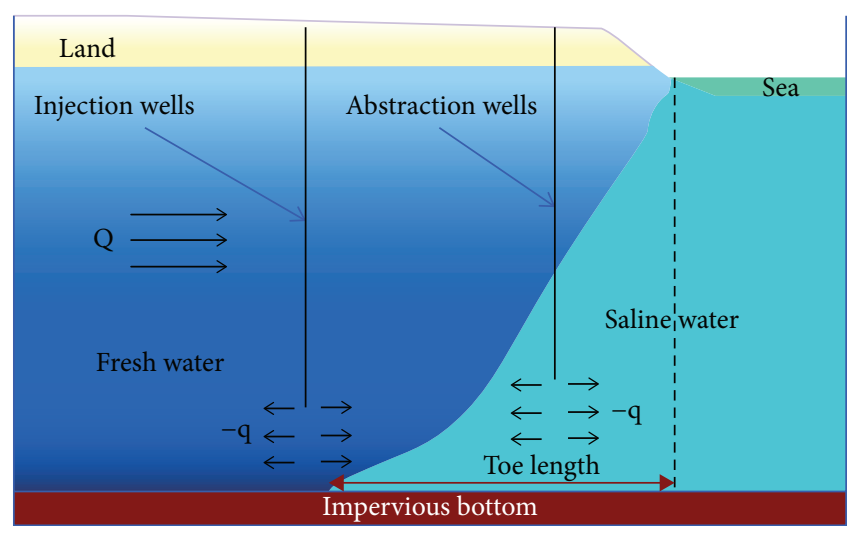

Figure 1: Simplified diagrams showing the injection wells and abstraction wells for the restoration of salt water.

underground salt water body in the vertical direction. The model consists of a main body and a device of water supply (Figure 2). The main body of the model is a hollow cylinder made in organic glass (the outer diameter is $7 \mathrm{~cm}$, the inner diameter is $5 \mathrm{~cm}$, and the height is $120 \mathrm{~cm}$ ). In order to ensure the air tightness of the test, both ends of the cylinder are sealed by the rubber plug. The upper rubber plug and the lower one are punctured by a needle, as the inlet and outlet. The inner part is filled with medium containing water, and the standard sand is used to fill the sand column. A singlelayer geotextile cushion is used on the top and bottom of the sand column, in order to ensure that the surface inlet will not be blocked by the sand particles. There are three holes (labeled No. A, No. B, and No. C) arranged in the lateral wall of the plexiglass tube. They were $30 \mathrm{~cm}$ apart from each other, which can be opened and closed under control. They can monitor the variation of concentration of flow in the model. The device for water supply is controlled by a peristaltic pump, and the freshwater can be injected into the sand column at a constant flow rate.

2.2. Test Materials. The sand samples are standard sand, produced by ISO Company, Xiamen City, China. The particle size of the sand sample is between 2 and $3 \mathrm{~mm}$. The hydraulic conductivity of the sand is $2.2 \times 10^{-4} \mathrm{~m} / \mathrm{s}$, obtained from the constant head permeameter. The deionized water used to be freshwater, which is made in a laboratory. The concentration of freshwater is $0 \mathrm{~g} / \mathrm{L}$, the density of it is $1.00 \times 10^{3} \mathrm{~kg} / \mathrm{m}^{3}$, and the electrical conductivity of it is $0 \mathrm{mS} / \mathrm{cm}$. The salt water is configured by deionized water and sodium chloride (analytical purity). The concentration, density, and electrical conductivity of the salt water are $9.0 \mathrm{~g} / \mathrm{L}, 1.01 \times 10^{3} \mathrm{~kg} / \mathrm{m}^{3}$, and $15.13 \mathrm{mS} / \mathrm{cm}$, respectively.

2.3. Flow Chart. The tests are carried out to simulate the variation of variable density flow and solute transport in the column, by injecting the low-density freshwater at a constant flux into the sand column, which is saturated by the high-density salt water. The difference of flow and solute migration in the sand column under the condition of vertical injection of freshwater in different directions is discussed. The flow chart is as follows: 


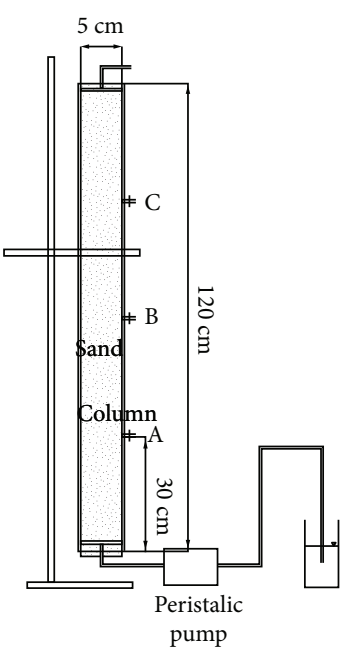

(a)

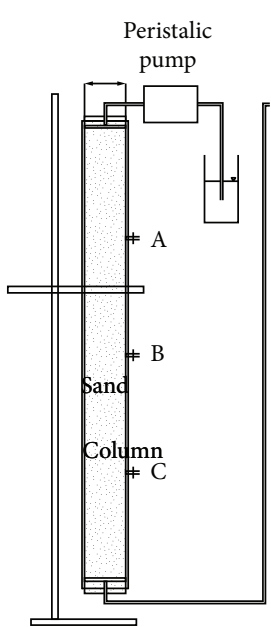

(b)

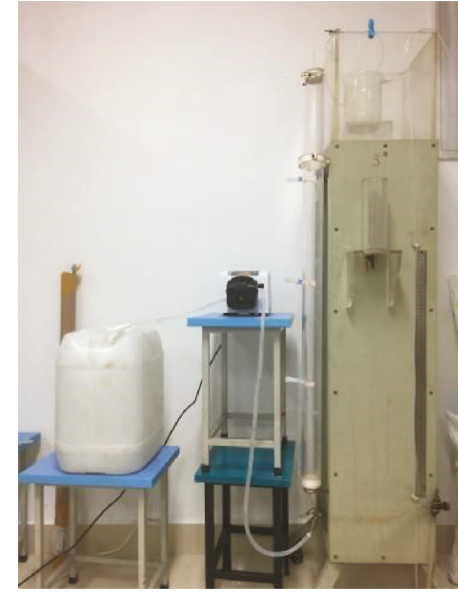

Figure 2: Schematic diagram and physical map of the test model: (a) schematic diagram and (b) physical diagram.

Step 1 The standard curve of the relationship between $\mathrm{Cl}^{-}$concentration and electrical conductivity is obtained, by configuring different concentrations of standard $\mathrm{NaCl}$ solution and measuring its compensated electrical conductivity (i.e., the electrical conductivity of the solution at the temperature below $25^{\circ} \mathrm{C}$ ). The linear relationship between $\mathrm{Cl}^{-}$concentration and electrical conductivity is obtained by the least square method

Step 2 Close the outlet and sampling hole, and verify the air tightness of the device. Use a 702 silicone rubber to seal it if there is an unsealed area

Step 3 The $\mathrm{NaCl}$ solution with the concentration of $9 \mathrm{~g} / \mathrm{L}$ is filled into the plexiglass tube. The liquid level is less than $5 \mathrm{~cm}$ at each time. Then, pour the sand slowly into the column, and stir it continuously, in order to make the distribution of sand samples evenly and the bubble out of the pore. Stop it when the sand reaches the liquid level at each time, and knock the outer wall to make the sand deposit. When the internal settlement of the sand column is less than $1 \mathrm{~mm}$ within $5 \mathrm{~min}$, continue to fill the salt water and sand samples, and the above step is repeated. Cover the geotextile and seal the model when the sand column is close to the outlet

Step 4 Let the model be static, and make the settlement of sand layer in the model completely (i.e., the settlement of sand column is less than $1 \mathrm{~mm}$ within $1 \mathrm{~h})$. The water head tends to stabilize, and the variation of water head in the piezometer tube is less than $5 \mathrm{~mm}$ in $1 \mathrm{~h}$

Step 5 Open the inlet and outlet, when the height of the outlet is stable at $1.2 \mathrm{~m}$. The model is injected with freshwater by the peristaltic pump, at the predetermined water injection rate. Water samples are taken at the sampling hole and the outlet every 20 minutes during the test. The variation of electrical conductivity of the water samples is observed. The specific sampling time is determined based on the water injection rate. However, there should be three or more valid data points on the drop curve of concentration at each observation point. When the concentration of water sample at the outlet reaches below $1 \mathrm{~g} / \mathrm{L}$ for three times, it is considered that the salt water has been repaired and the test is completed. Then, the distribution of concentration in the model is obtained by the $\mathrm{Cl}^{-}$concentration

Step 6 The water in the model should be emptied, and the sand column should be washed repeatedly with tap water after the test. Change the test conditions, and repeat the above steps for the next test

2.4. Test Schemes. Two groups of compared tests are carried out, by changing the direction of water injection. The water injection direction is set to be the directions of gravity (top injection) and reverse gravity (bottom injection), respectively. There are six tests in each group. The injection rate in each group is $2 \mathrm{~mL} / \mathrm{min}, 5 \mathrm{~mL} / \mathrm{min}, 8 \mathrm{~mL} / \mathrm{min}, 10 \mathrm{~mL} / \mathrm{min}$, $20 \mathrm{~mL} / \mathrm{min}$, and $40 \mathrm{~mL} / \mathrm{min}$, respectively. The water samples in the monitoring hole and the outlet are collected at the interval between $5 \mathrm{~min}$ and $30 \mathrm{~min}$ during the test. When the water injection rate is $40 \mathrm{~mL} / \mathrm{min}$, the sampling interval is too short to collect the water sample at the monitoring hole, so that the water sample at the outlet is taken. The test schemes are listed in Table 1.

\section{Numerical Simulations of Variable Density Flow and Solute Transport}

3.1. Mathematical Model. In order to simulate the vertical isokinetic flow of variable density flow, a physical model as shown in Figure 2 is designed. The coordinate origin $O$ is 
TABLE 1: Test schemes.

\begin{tabular}{|c|c|c|c|c|c|}
\hline Test group number & Direction of water injection & Test no. & $\begin{array}{c}\text { Flux of water } \\
\text { injection }(\mathrm{mL} / \mathrm{min})\end{array}$ & $\begin{array}{c}\text { Sampling } \\
\text { interval (min) }\end{array}$ & $\begin{array}{l}\text { Duration of } \\
\text { tests (min) }\end{array}$ \\
\hline \multirow{6}{*}{ Group 1} & \multirow{6}{*}{$\begin{array}{l}\text { The direction of gravity } \\
\text { (from up to down) }\end{array}$} & 1 & 2 & 30 & 900 \\
\hline & & 2 & 5 & 15 & 400 \\
\hline & & 3 & 8 & 10 & 240 \\
\hline & & 4 & 10 & 10 & 200 \\
\hline & & 5 & 20 & 5 & 100 \\
\hline & & 6 & 40 & 2 & 50 \\
\hline \multirow{6}{*}{ Group 2} & \multirow{6}{*}{$\begin{array}{l}\text { The direction of reverse gravity } \\
\text { (from down to up) }\end{array}$} & 7 & 2 & 30 & 900 \\
\hline & & 8 & 5 & 15 & 400 \\
\hline & & 9 & 8 & 10 & 240 \\
\hline & & 10 & 10 & 10 & 200 \\
\hline & & 11 & 20 & 5 & 100 \\
\hline & & 12 & 40 & 2 & 50 \\
\hline
\end{tabular}

taken on the lower surface of the sand column, the coordinate $Z$ is vertical upward, and the length of the test section is $L$. Based on Guo and Langevin's study [18], the mathematical model of one-dimensional variable density flow of the saturated sand column should be

$$
\frac{\partial}{\partial z}\left[K\left(\frac{\partial H}{\partial z}+\eta c\right)\right]+\frac{\rho_{s}}{\rho_{0}} q=S_{s} \frac{\partial H}{\partial t}+n_{e} \eta \frac{\partial c}{\partial t},
$$

where $K$ is the hydraulic conductivity of porous media $\left[\mathrm{LT}^{-1}\right], H$ is the equivalent freshwater head (water head of pressure tube) $[\mathrm{L}], \rho_{0}$ is the density of freshwater $\left[\mathrm{ML}^{-3}\right]$, $C$ is the concentration of $\mathrm{Cl}^{-}$in the mixed solution $\left[\mathrm{ML}^{-3}\right]$, $\rho_{S}$ is the density of the mixed solution $\left[\mathrm{ML}^{-3}\right], n_{e}$ is the effective porosity, $S_{s}$ is the specific storage coefficient $\left[\mathrm{L}^{-1}\right], q$ is the flow rate of the porous medium in unit volume $\left[\mathrm{T}^{-1}\right]$, and $\eta$ the density coupling coefficient, which is defined as

$$
\eta=\frac{\rho_{s}-\rho_{0}}{\rho_{0} C_{s}}
$$

where $C_{s}$ is the $\mathrm{Cl}^{-}$concentration in the sea water $\left[\mathrm{ML}^{-3}\right]$.

The governing equation for salt transport in the simulations is

$$
\frac{\partial}{\partial z}\left(D \frac{\partial c}{\partial z}\right)-\frac{\partial(v c)}{\partial z}=\frac{\partial c}{\partial t}
$$

where $D$ is the dispersion coefficient $\left[\mathrm{L}^{2} \mathrm{~T}^{-1}\right]$ and $v$ is the average velocity of the porous medium $\left[\mathrm{LT}^{-1}\right]$, which is defined as

$$
v=-\frac{K}{n_{e}}\left(\frac{\partial H}{\partial \mathrm{z}}\right)
$$

When the injected water flows from top to bottom, the initial water head in the sand column is $H_{0}$, and the concentration is $C_{0}$. The flow rate on per unit area of the upper boundary of the sand column is $q_{0}$, and the concentration on it is 0 . The water head on the lower boundary of the sand column is $H_{0}$, and the concentration boundary on it is the variable concentration boundary. That is,

$$
\left\{\begin{array}{l}
H(z, 0)=H_{0}, \quad 0 \leq z \leq l \\
\left.K \frac{\partial H}{\partial z}\right|_{z=l}=q_{0} \\
H(0, t)=H_{0}, \quad t \geq 0 \\
C(z, 0)=C_{0}, \quad 0 \leq z \leq l \\
C(l, t)=0, \quad t \geq 0 \\
\left.\frac{\partial C}{\partial z}\right|_{z=0}=0
\end{array}\right.
$$

In the other scheme, when the injected water flows from down to up, the initial water head in the sand column is $H_{0}$, and the concentration is $C_{0}$. The water head on the upper boundary of the sand column is $H_{0}$, and the concentration boundary on it is the variable concentration boundary. The flow rate on per unit area of lower boundary of the sand column is $q_{0}$, and the concentration on it is 0 . That is,

$$
\left\{\begin{array}{l}
H(z, 0)=H_{0}, \quad 0 \leq z \leq l \\
-\left.K \frac{\partial H}{\partial z}\right|_{z=0}=q_{0} \\
H(l, t)=H_{0}, \quad t \geq 0 \\
C(z, 0)=C_{0}, \quad 0 \leq z \leq l \\
C(0, t)=0, \quad t \geq 0 \\
\frac{\partial C}{\partial z}=0, \quad z=l
\end{array}\right.
$$

3.2. Numerical Simulation Method. The mathematical model is discretized by the finite difference method. In order to make the calculated results stable and convergent, an implicit finite difference scheme is constructed, which is detailed in 
the Appendix. The model is discretized into 120 200 nodes, and the calculation program is written in Fortran code. The program has visual processes of input and output data. It is convenient to simulate the salt water migration in the sand column. The parameter optimization is calculated with PEST (parameter estimate) code [19].

\section{Comparison between the Experimental and Numerical Results}

4.1. Analysis of Experimental Data. The observation data of the two group tests (six times for each group) were obtained, by changing the direction of water injection and flow rate. The breakthrough curves were plotted as shown in Figures 3 and 4.

From the breakthrough curves of the tests, it can be seen that the variation trend of concentration at each monitoring hole is similar to that at the outlet, during the experiment for freshwater flowing from different directions at different rates. The $\mathrm{Cl}^{-}$concentration decreases from the inlet to the outlet and finally reaches zero. The variation of $\mathrm{Cl}^{-}$concentration is consistent with the decline of concentration in the breakthrough curve. This indicates that the freshwater pushed forward and the salt water is removed, when the vertical water injection is carried out. There is a transitional zone between the freshwater and salt water, and the width of the transitional zone is directly proportional to the repair time. It can be found that the $\mathrm{Cl}^{-}$concentration changes fast and then slowly at each point, which means the slope of the first half of the descending curve is large. When the $\mathrm{Cl}^{-}$concentration decreased to about $1 \mathrm{~g} / \mathrm{L}$, the concentration changes slowly and the slope of the curve decreases gradually. The breakthrough curves of the comparison tests are different, when the direction of water injection and water injection rate change. Further analysis should be studied.

\subsection{Analysis of the Tests}

4.2.1. Along the Direction of Gravity. Figure 3(b) shows that the concentration at each point from the inlet to the outlet begins to decrease from $45 \mathrm{~min}, 90 \mathrm{~min}, 150 \mathrm{~min}$, and $195 \mathrm{~min}$ and, at that time, the rate of water injection is $5 \mathrm{~mL} / \mathrm{min}$. The concentration at each point from the inlet to the outlet reaches its standard concentration of $1 \mathrm{~g} / \mathrm{L}$ at $75 \mathrm{~min}, 135 \mathrm{~min}, 210 \mathrm{~min}$, and $255 \mathrm{~min}$, respectively. The time for restoration increased from the inlet to the outlet. It indicates that the transitional zone between salt water and freshwater widens progressively and tends to be stable, while the freshwater pushes forward the salt water continuously, during the experiment of water injection along the direction of gravity.

4.2.2. Along the Direction of Reverse Gravity. Figure 4(b) reports that the concentration at each point from the inlet to the outlet begins to decrease from $30 \mathrm{~min}, 75 \mathrm{~min}, 105 \mathrm{~min}$, and $135 \mathrm{~min}$, when the water injection rate is $5 \mathrm{~mL} / \mathrm{min}$. The concentration at each point from the inlet to outlet can reach its standard concentration of $1 \mathrm{~g} / \mathrm{L}$ at $105 \mathrm{~min}$, $165 \mathrm{~min}, 225 \mathrm{~min}$, and $315 \mathrm{~min}$, respectively. It demonstrates that the transitional zone between salt water and freshwater widens progressively and tends to be stable, while the freshwater pushes forward the salt water continuously. The amplitude of the variation of transitional zone increases gradually, during the experiment of water injection in the inverse direction of gravity.

\subsubsection{Comparison of Different Directions of Water Injection.} From Figures 3(b) and 4(b), one can see that when the water is injected in the direction of reverse gravity, the time when the concentration begins to change is 15 60 min earlier than that in the gravity direction. The time for the restoration of salt water in the reverse gravity direction is 30 60 min longer than that in the direction of gravity. The time for restoration at each point is between 30 and 60 minutes when the water is injected along the gravity direction, which changes not too relative to the whole test time. When the water is injected in the direction of reverse gravity, the time for restoration for salt water at each point increases along the direction of water injection with the push of freshwater. The time for restoration is between $75 \mathrm{~min}$ and $180 \mathrm{~min}$ when the water is injected in the direction of reverse gravity, which is about two or three times of that in the direction of the gravity.

In order to exclude the effect of time duration on the test result, when the water injection rate is $5 \mathrm{~mL} / \mathrm{min}$, the dimensionless time and concentration (the monitored concentration divided by the initial concentration at each point) of the tests are shown in Figure 5. When the water is injected in the direction of gravity, the concentration at each point decreases steeply, and the variation of the slope is little. When the water is injected in the direction of reverse gravity, the change of concentration at each point slows down gradually. The slope of the concentration curve at the outlet is half of that of the curve at the monitoring point A. It indicates that the effect of hydrodynamic dispersion is relatively weak, when the freshwater is injected in the direction of gravity. It leads to little change in the transition zone during the test. When the water is injected in a reverse gravity direction, the hydrodynamic dispersion is larger than that in the direction of gravity. The concentration at each point decreases rapidly, and the time for restoration becomes long. The slope of the descending curve becomes smaller, and the transition zone widens gradually during the test.

\subsection{The Effect of Water Injection Rate on the Breakthrough Curve}

4.3.1. Along the Direction of Gravity. In order to analyze the effect of different rates of water injection on salt water variation in the sand column, the breakthrough curves for different water injection rates as shown in Figure 3 are compared. It can be seen that when the water injection rate is $2 \mathrm{~mL} / \mathrm{min}, 5 \mathrm{~mL} / \mathrm{min}, 8 \mathrm{~mL} / \mathrm{min}, 10 \mathrm{~mL} / \mathrm{min}, 20 \mathrm{~mL} / \mathrm{min}$, and $40 \mathrm{~mL} / \mathrm{min}$, the corresponding test time is $690 \mathrm{~min}$, $265 \mathrm{~min}, 160 \mathrm{~min}, 130 \mathrm{~min}, 55 \mathrm{~min}$, and $28 \mathrm{~min}$, respectively. That is, the smaller the rate of water injection is, the longer the time of tests is used. This is because the restoration for salt water in the sand column is mainly driven by the hydrodynamic force. When the water injection rate becomes 


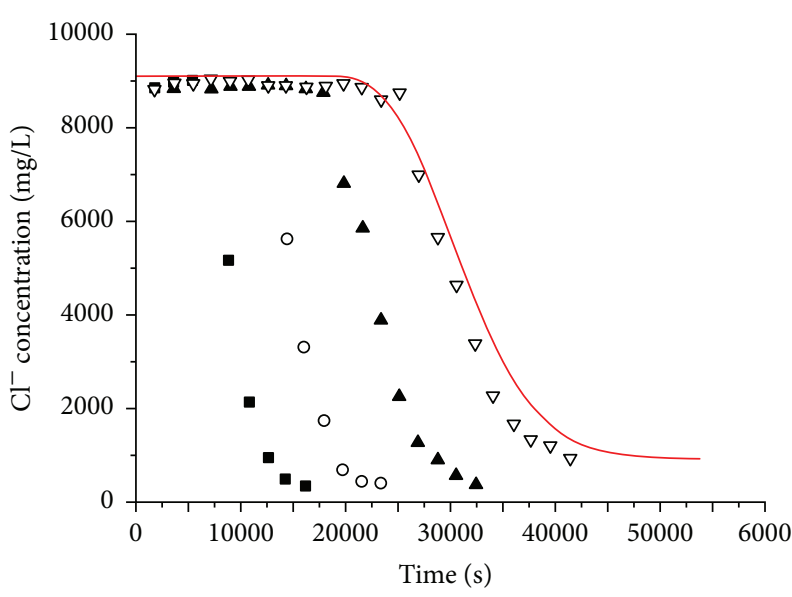

(a)

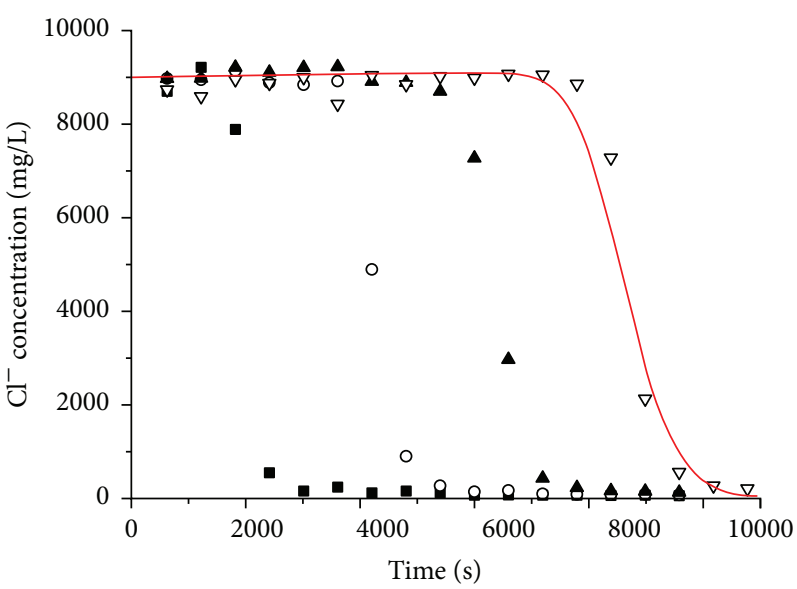

(c)

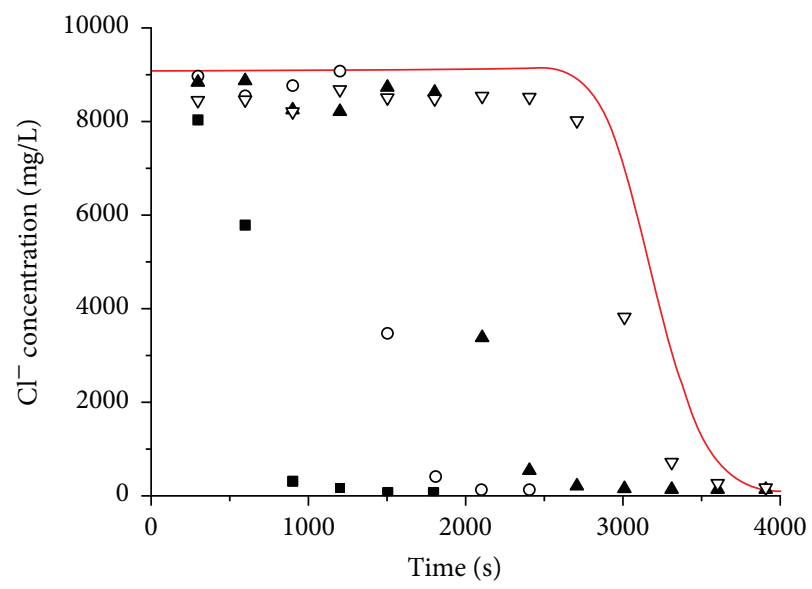

(e)

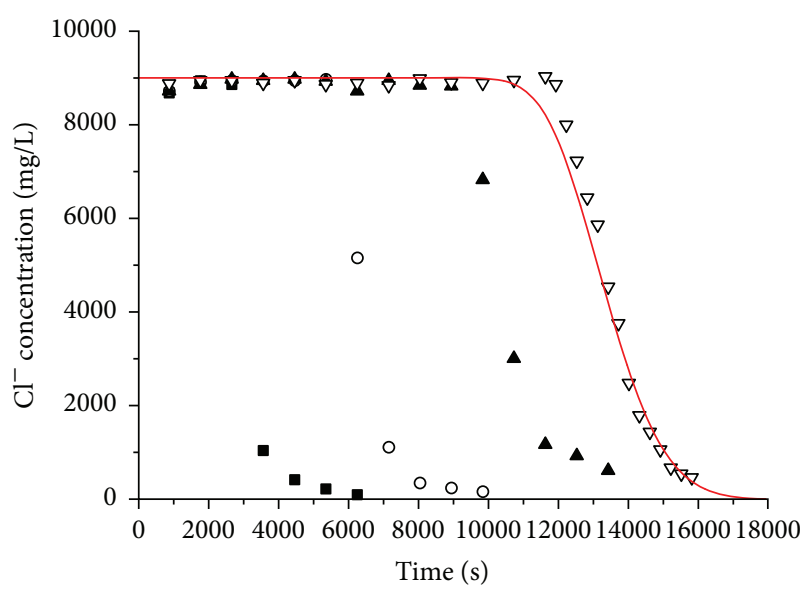

(b)

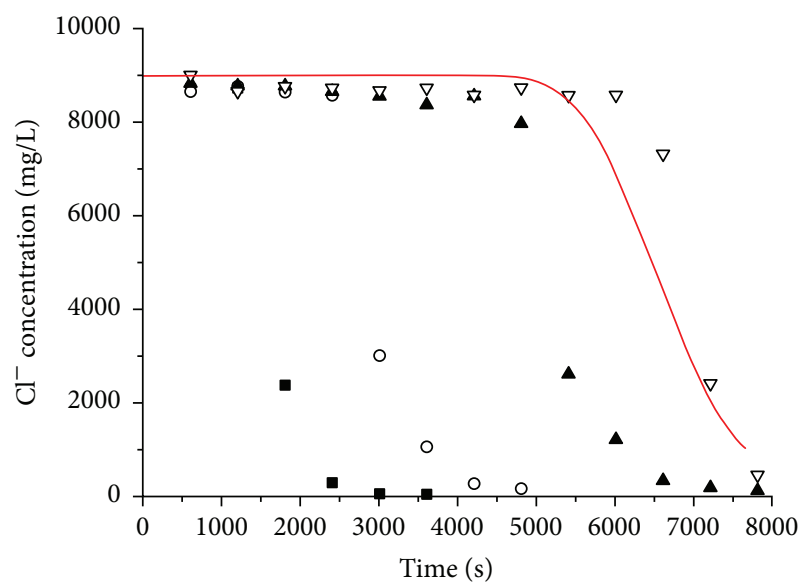

(d)

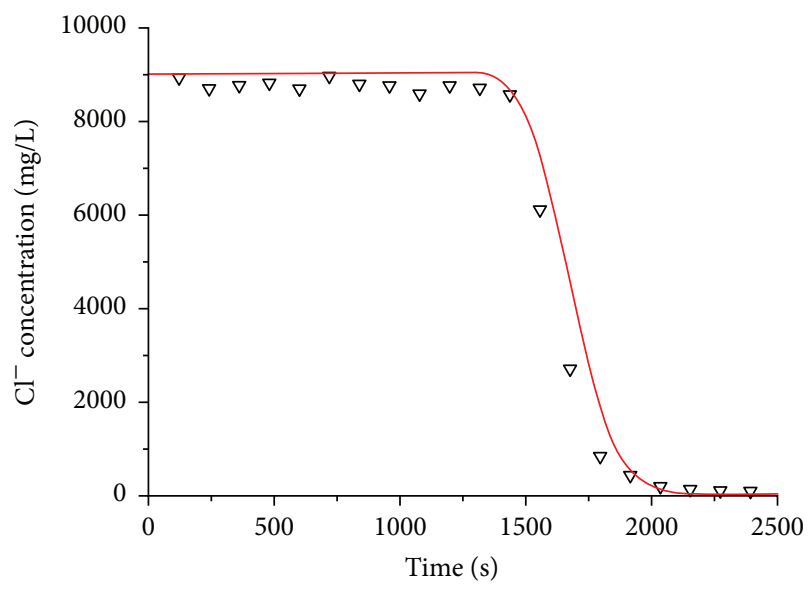

(f)

Figure 3: Curves and fitting results of $\mathrm{Cl}^{-}$at the monitoring point and outlet indifferent gravity direction: (a) $2 \mathrm{~mL} / \mathrm{min}$, (b) $5 \mathrm{~mL} / \mathrm{min}$, (c) $8 \mathrm{~mL} / \mathrm{min}$, (d) $10 \mathrm{~mL} / \mathrm{min}$, (e) $20 \mathrm{~mL} / \mathrm{min}$, and (f) $40 \mathrm{~mL} / \mathrm{min}$.

smaller, the actual flow velocity decreases, and the velocity of saltwater movement driven by the hydrodynamic force decreases, which leads to the longer time of the test.

When the water is injected in the direction of gravity under the condition of different rates, the time for restoration at the outlet for each test was $270 \mathrm{~min}, 60 \mathrm{~min}, 30 \mathrm{~min}$,
$30 \mathrm{~min}, 15 \mathrm{~min}$, and $6 \mathrm{~min}$, respectively, which accounted for the percentage of $39 \%, 23 \%, 19 \%, 23 \%, 27 \%$, and $21 \%$ of the total test time. It can be seen that when the water injection rate is greater than $2 \mathrm{~mL} / \mathrm{min}$, the time for restoration at the outlet for each test takes up $20 \%$ of the total test time. It indicates that the width of the transitional zone varies 


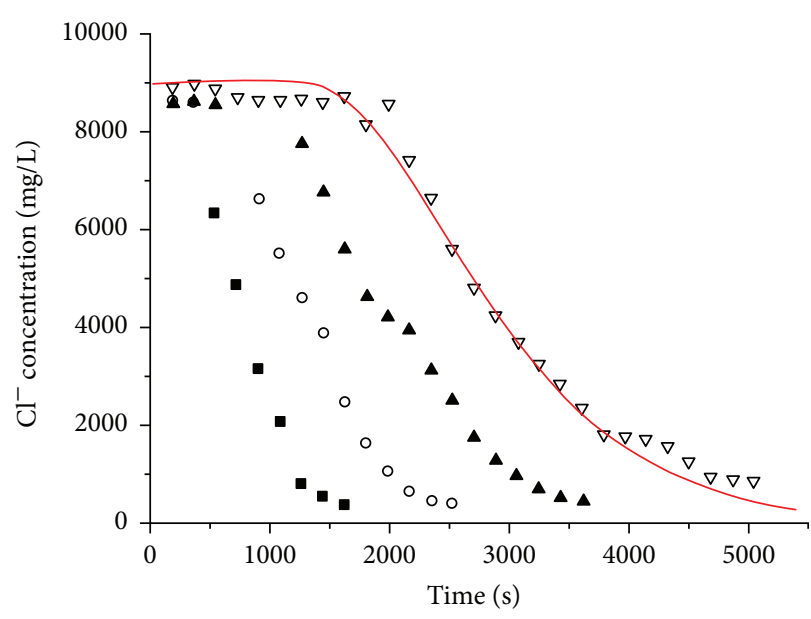

(a)

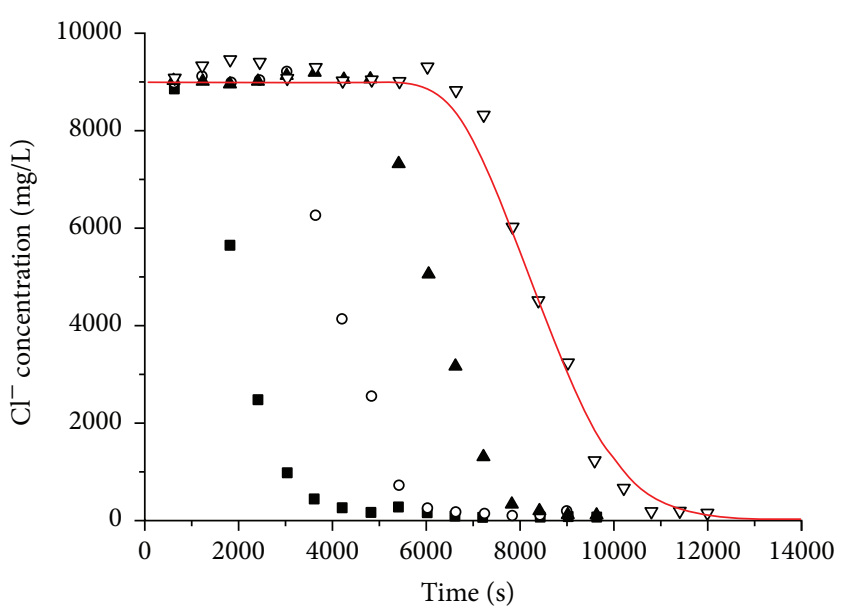

(c)

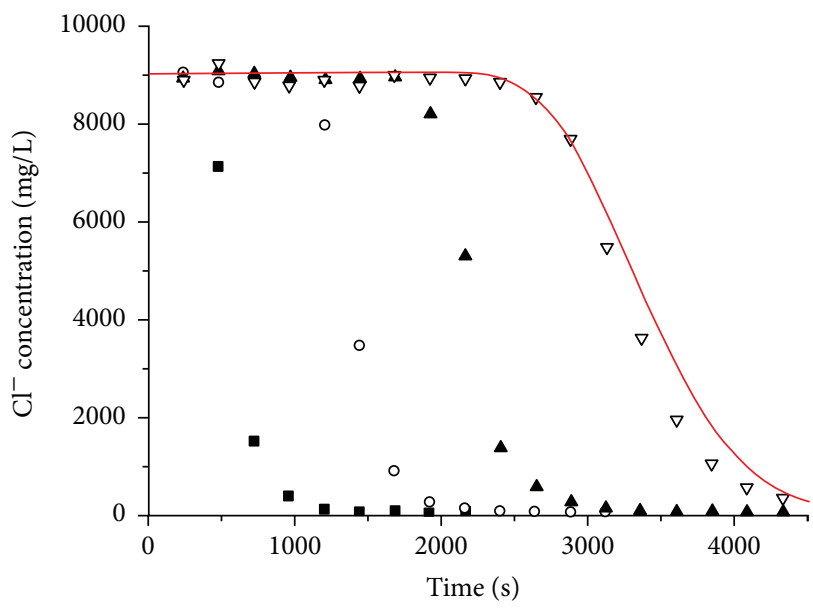

(e)

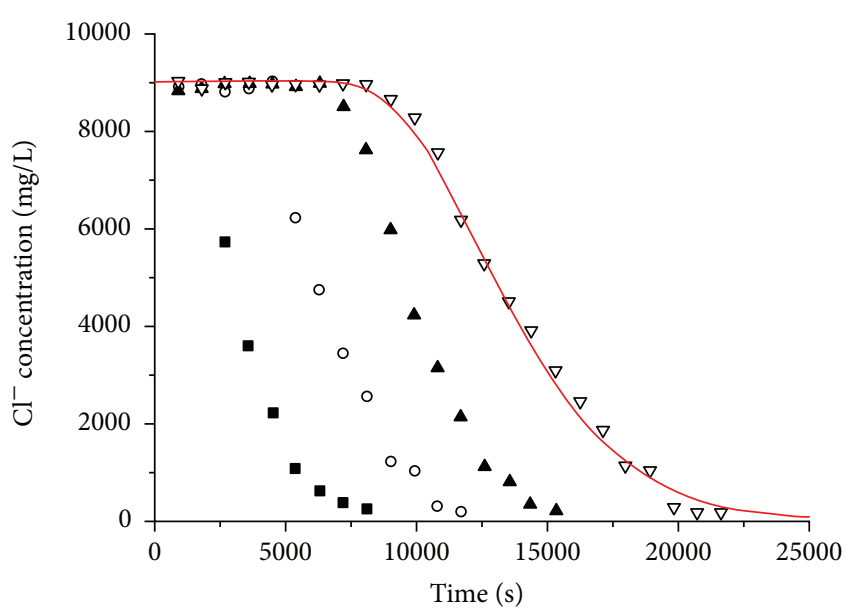

(b)

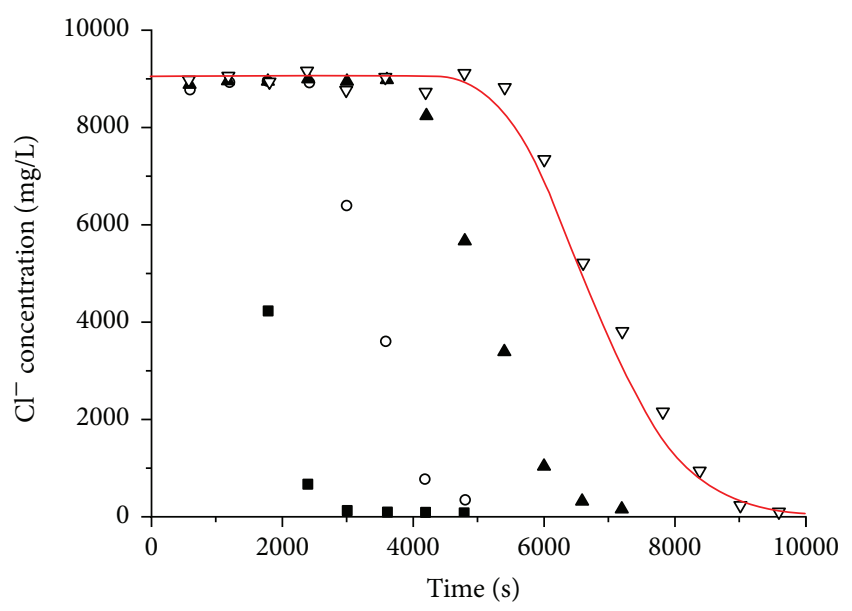

(d)

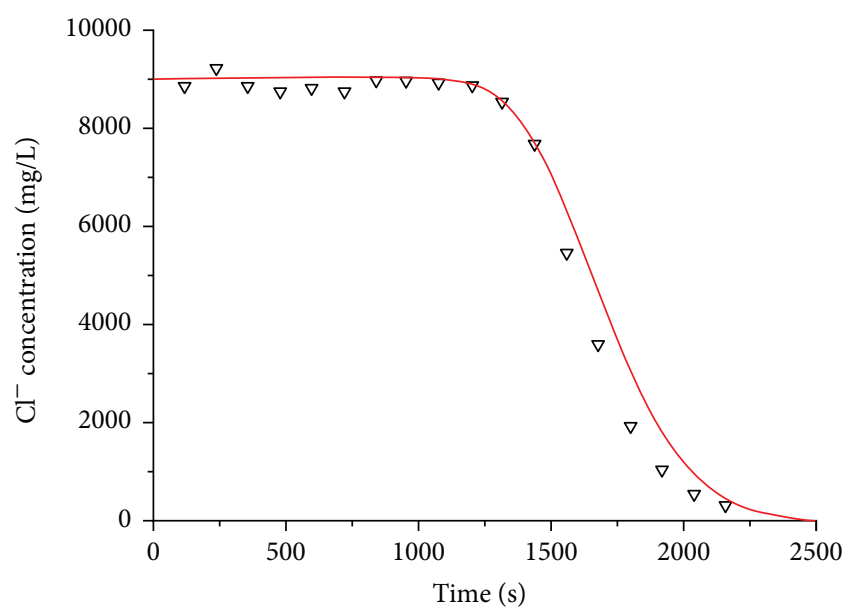

(f)

FIGURE 4: Curves and fitting results of test hole and outlet $\mathrm{Cl}^{-}$in different directions in reverse gravity direction: (a) $2 \mathrm{~mL} / \mathrm{min}$, (b) $5 \mathrm{~mL} / \mathrm{min}$, (c) $8 \mathrm{~mL} / \mathrm{min}$, (d) $10 \mathrm{~mL} / \mathrm{min}$, (e) $20 \mathrm{~mL} / \mathrm{min}$, and (f) $40 \mathrm{~mL} / \mathrm{min}$. $\mathbf{a}$ : monitoring hole A; O: monitoring hole B; $\mathbf{\Delta}$ : monitoring hole C; $\nabla$ : outlet; - : analog value.

little with the injection rate, when the water is injected in the direction of gravity. When the water injection rate is $2 \mathrm{~mL} / \mathrm{min}$, the width of the transitional zone increases, because of the obvious molecular diffusion.
4.3.2. Along the Inverse Direction of Gravity. The breakthrough curves for different water injection rates as shown in Figure 4 are compared, and the effect of water injection rate on the variation of salt water in the sand column is 


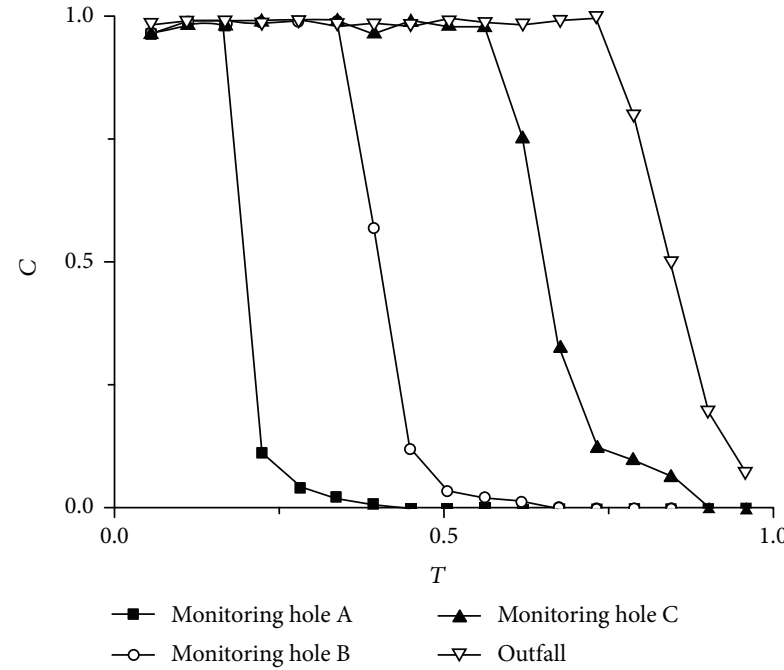

(a)

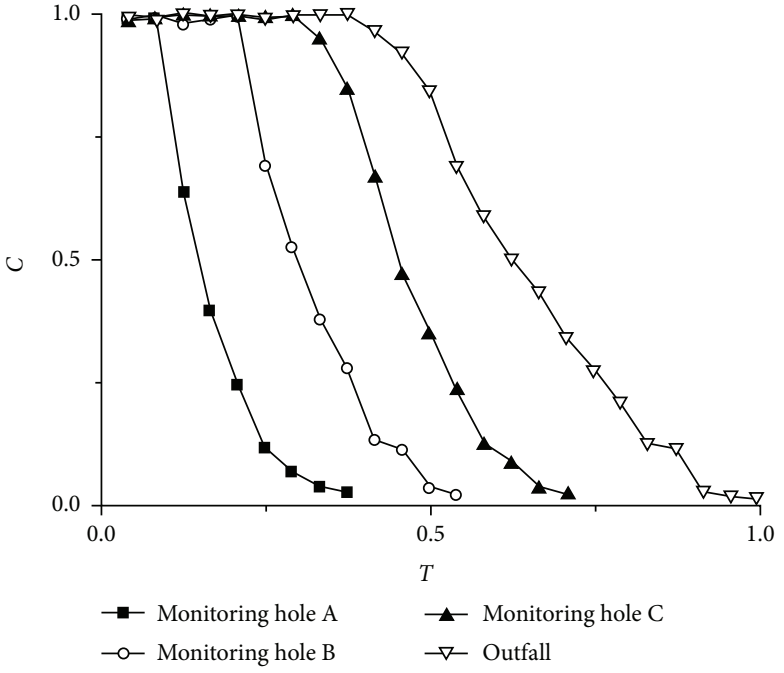

(b)

FIGURE 5: The dimensionless variation curve when the water injection rate is $5 \mathrm{~mL} / \mathrm{min}$ : (a) gravity direction and (b) reverse gravity direction.

analyzed. It can be seen that when the water injection rate is $2 \mathrm{~mL} / \mathrm{min}, 5 \mathrm{~mL} / \mathrm{min}, 8 \mathrm{~mL} / \mathrm{min}, 10 \mathrm{~mL} / \mathrm{min}, 20 \mathrm{~mL} / \mathrm{min}$, and $40 \mathrm{~mL} / \mathrm{min}$, the corresponding test time is $780 \mathrm{~min}, 330 \mathrm{~min}$, $170 \mathrm{~min}, 140 \mathrm{~min}, 60 \mathrm{~min}$, and $34 \mathrm{~min}$, respectively. It indicates that when the water is injected in the inverse direction of gravity, the time of test will also increase with the decrease of the water injection rate.

The time for the restoration of the test at the outlet under the condition of different water injection rates in the reverse gravity direction was $510 \mathrm{~min}, 195 \mathrm{~min}, 80 \mathrm{~min}, 60 \mathrm{~min}$, $20 \mathrm{~min}$, and $12 \mathrm{~min}$, respectively, which accounted for $65 \%$, $59 \%, 47 \%, 43 \%, 33 \%$, and $35 \%$ of the total time. It can be seen that the smaller the water injection rate is, the wider the transitional zone between salt water and freshwater will be, and the longer the time for restoration will be.

\subsubsection{Comparison of Different Directions of Water Injection.} Under the different water injection directions, the influence of different water injection rates on the remediation of salt water is different. From the above results, we can see that there is a little difference between the two directions of water injection, when the water injection rate is large. When the water injection rate is smaller, the difference in test time becomes more apparent. When the water injection rate is $2 \mathrm{~mL} / \mathrm{min}$, the difference reaches its maximum value $13 \%$. It indicates that the test time of water injection in the direction of reverse gravity is generally longer than that in the direction of gravity, and the difference between the two conditions is becoming more and more obvious with the decrease of the water injection rate.

In order to eliminate the influence of experimental time on the results, the concentration changes of $20 \mathrm{~mL} / \mathrm{min}$, $10 \mathrm{~mL} / \mathrm{min}, 5 \mathrm{~mL} / \mathrm{min}$, and $2 \mathrm{~mL} / \mathrm{min}$ at the outlet are selected. Then, the time and concentration are dimensionless, and the curves are shown in Figure 6. It can be seen that when the water injection rate is $20 \mathrm{~mL} / \mathrm{min}$, the difference of curves in the two directions are little. When the water injection rate decreases, the difference of curves in the two directions of water injection becomes more evident. It can be clearly seen that the curve begins to fall early in the reverse gravity direction, the decline rate of the curve is slow, and the time of reaching restoration standard is late. It indicates that the hydrodynamic dispersion phenomenon is relatively obvious, and the transitional zone is wider in the water injection of the reverse gravity direction. It increases with the decrease of the water injection rate. However, the effect of molecular diffusion becomes more prominent when the water injection rate reaches $2 \mathrm{~mL} / \mathrm{min}$, which makes the two directions of water injection becoming closer.

4.4. Parameter Fitting Analysis and Verification. The parameters of the model include the hydraulic conductivity $K$, storativity $S_{s}$, effective porosity $n_{e}$, and dispersion coefficient $D$. The hydraulic conductivity $K$ was measured by the constant head permeameter. The storativity $S_{s}$ is an insensitive coefficient, which can be taken as an empirical value combined with the previous numerical calculation. When the initial condition and boundary condition of the model are given, the dispersion coefficient and effective porosity were adjusted by PEST code (parameter estimate), which make the calculated concentration fitted well with the observed data. Then, the dispersivity of the sand column was calculated by the average velocity of the pore and dispersion coefficient. After the identification and calibration of the model, the test parameters of each group are shown in Tables 2 and 3. The calculated parameters are taken into the model, and the fitting results are shown in Figures 3 and 4 . The results of the fitting show that the standard deviations of three tests are under $0.5 \mathrm{~g} / \mathrm{L}$, which account for $25 \%$ of the total number of tests. The standard deviations of $58 \%$ percentage tests are between $0.5 \mathrm{~g} / \mathrm{L}$ and $1.0 \mathrm{~g} / \mathrm{L}$, and $17 \%$ percentage tests are greater than $1.0 \mathrm{~g} / \mathrm{L}$, whereas the maximum standard deviation is not more than $1.5 \mathrm{~g} / \mathrm{L}$. The results show that the model can fit well with the solute transport in the test, and the optimized parameters are reliable. 


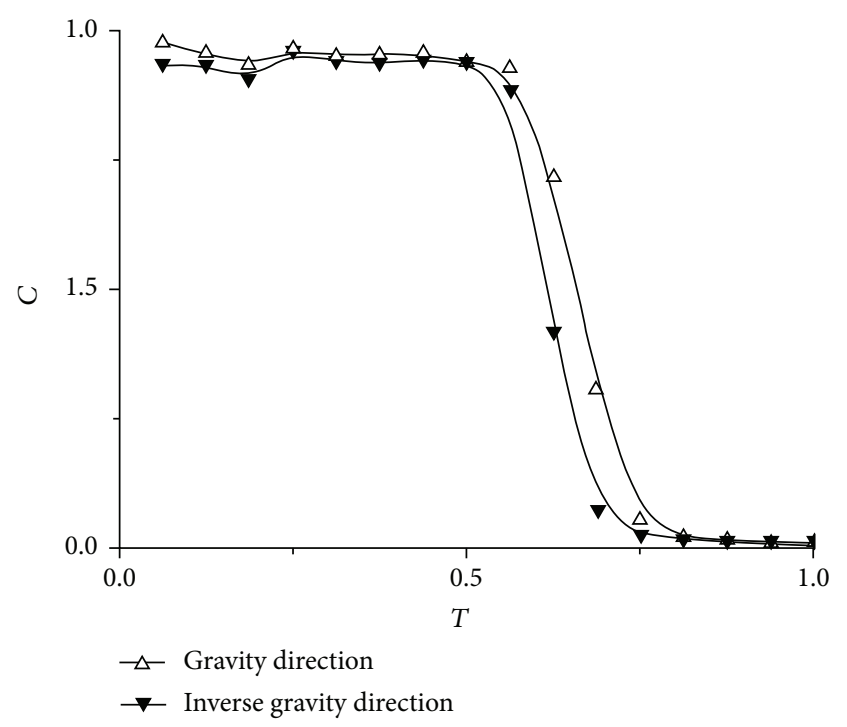

(a)

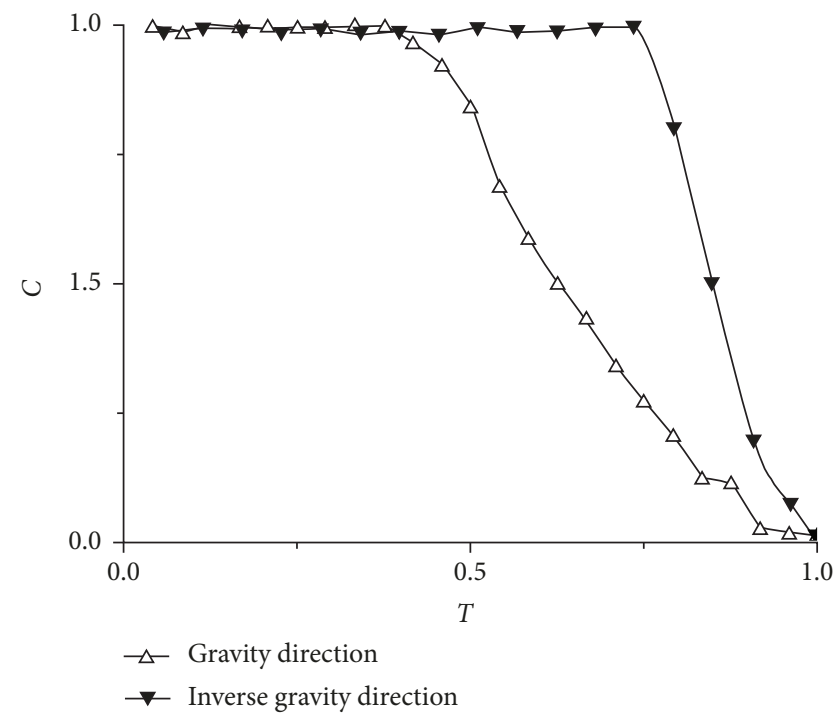

(c)

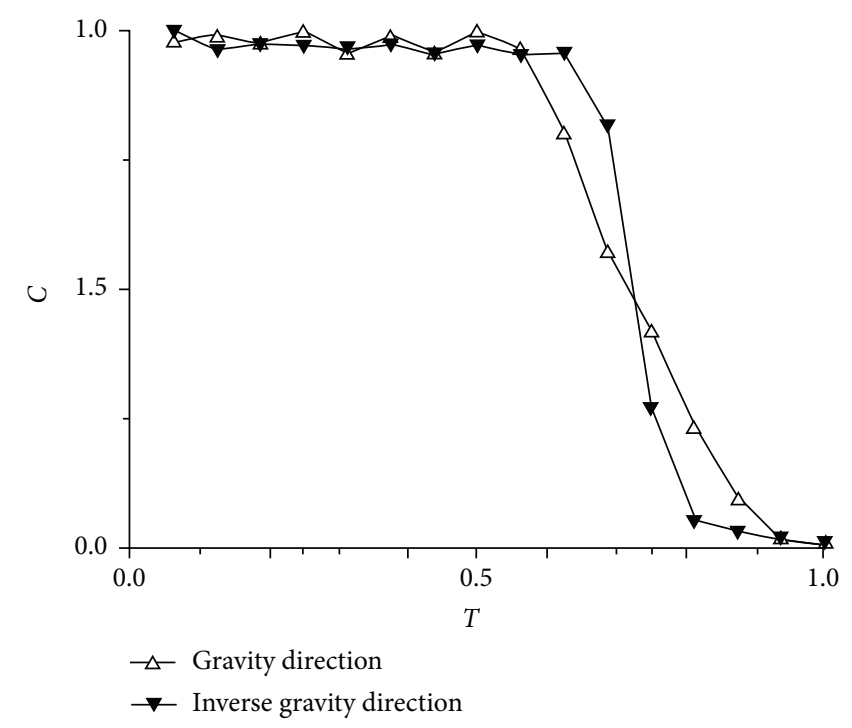

(b)

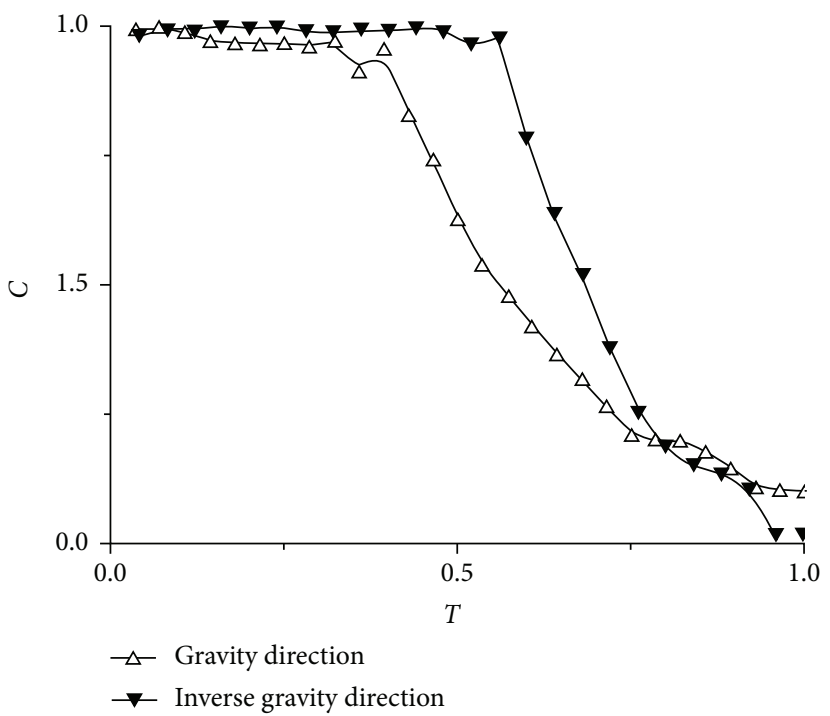

(d)

FIgURE 6: The dimensionless curve of concentration variation at the outlet for each contrast tests: (a) $20 \mathrm{~mL} / \mathrm{min},(\mathrm{b}) 10 \mathrm{~mL} / \mathrm{min}$, (c) $5 \mathrm{~mL} / \mathrm{min}$, and (d) $2 \mathrm{~mL} / \mathrm{min}$.

TABle 2: Parameter optimization and error analysis along the direction of gravity.

\begin{tabular}{lccc}
\hline $\begin{array}{l}\text { Water injection } \\
\text { rate }\end{array}$ & $\begin{array}{c}\text { Dispersion } \\
\text { coefficient }\left(\mathrm{m}^{2} / \mathrm{s}\right)\end{array}$ & $\begin{array}{c}\text { Effective } \\
\text { porosity }(-)\end{array}$ & $\begin{array}{c}\text { Standard } \\
\text { deviation }(\mathrm{g} / \mathrm{L})\end{array}$ \\
\hline $2 \mathrm{~mL} / \mathrm{min}$ & $7.34 \times 10^{-7}$ & 0.44 & 0.64 \\
$5 \mathrm{~mL} / \mathrm{min}$ & $1.06 \times 10^{-6}$ & 0.47 & 0.66 \\
$8 \mathrm{~mL} / \mathrm{min}$ & $1.22 \times 10^{-6}$ & 0.49 & 0.47 \\
$10 \mathrm{~mL} / \mathrm{min}$ & $1.48 \times 10^{-6}$ & 0.47 & 1.42 \\
$20 \mathrm{~mL} / \mathrm{min}$ & $2.97 \times 10^{-6}$ & 0.44 & 0.85 \\
$40 \mathrm{~mL} / \mathrm{min}$ & $5.79 \times 10^{-6}$ & 0.47 & 0.39 \\
\hline
\end{tabular}

TABle 3: Parameter optimization and error analysis of reverse gravity direction.

\begin{tabular}{lccc}
\hline $\begin{array}{l}\text { Water injection } \\
\text { rate }\end{array}$ & $\begin{array}{c}\text { Dispersion } \\
\text { coefficient }\left(\mathrm{m}^{2} / \mathrm{s}\right)\end{array}$ & $\begin{array}{c}\text { Effective } \\
\text { porosity }(-)\end{array}$ & $\begin{array}{c}\text { Standard } \\
\text { deviation }(\mathrm{g} / \mathrm{L})\end{array}$ \\
\hline $2 \mathrm{~mL} / \mathrm{min}$ & $1.13 \times 10^{-6}$ & 0.43 & 0.71 \\
$5 \mathrm{~mL} / \mathrm{min}$ & $1.50 \times 10^{-6}$ & 0.46 & 0.52 \\
$8 \mathrm{~mL} / \mathrm{min}$ & $1.18 \times 10^{-6}$ & 0.47 & 0.95 \\
$10 \mathrm{~mL} / \mathrm{min}$ & $1.43 \times 10^{-6}$ & 0.48 & 1.18 \\
$20 \mathrm{~mL} / \mathrm{min}$ & $2.90 \times 10^{-6}$ & 0.44 & 0.53 \\
$40 \mathrm{~mL} / \mathrm{min}$ & $5.94 \times 10^{-6}$ & 0.47 & 0.28 \\
\hline
\end{tabular}




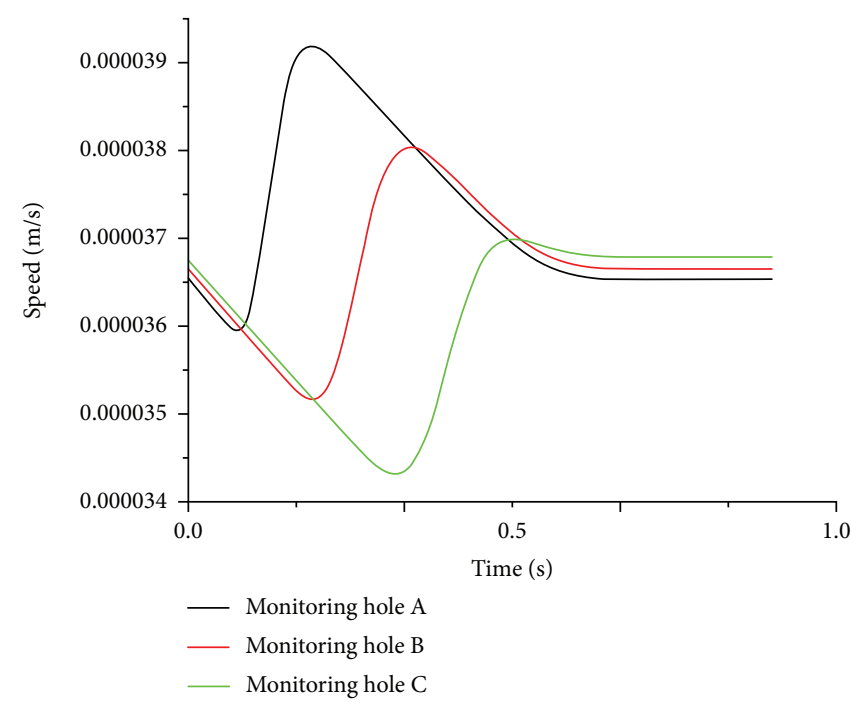

(a)

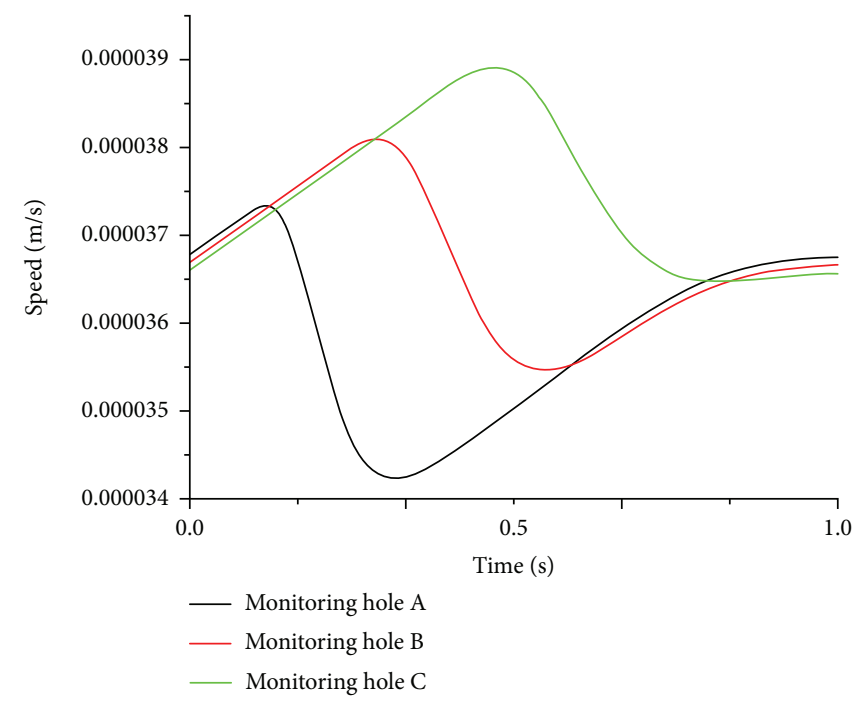

(b)

FIGURE 7: The velocity curve at the outlet in different injection directions when the injection rate is $2 \mathrm{~mL} / \mathrm{min}$ : (a) gravity direction and (b) reverse gravity direction.

TABLE 4: Average actual velocity at $\mathrm{A}, \mathrm{B}$, and $\mathrm{C}$ holes in each test.

\begin{tabular}{lrccc}
\hline $\begin{array}{l}\text { Water injection } \\
\text { rate }(\mathrm{mL} / \mathrm{min})\end{array}$ & $\begin{array}{c}\text { Direction of } \\
\text { water injection }\end{array}$ & $\begin{array}{c}\text { Actual mean velocity } \\
\text { at A (m/s) }\end{array}$ & $\begin{array}{c}\text { Actual mean velocity } \\
\text { at B (m/s) }\end{array}$ & $\begin{array}{c}\text { Actual mean velocity } \\
\text { at C (m/s) }\end{array}$ \\
\hline 2 & Gravity direction & $3.74 \times 10^{-5}$ & $3.67 \times 10^{-5}$ & $3.59 \times 10^{-5}$ \\
5 & Gravity direction & $8.76 \times 10^{-5}$ & $8.82 \times 10^{-5}$ & $8.87 \times 10^{-5}$ \\
8 & Gravity direction & $1.47 \times 10^{-4}$ & $1.47 \times 10^{-4}$ & $1.47 \times 10^{-4}$ \\
10 & Gravity direction & $1.83 \times 10^{-4}$ & $3.67 \times 10^{-4}$ & $1.83 \times 10^{-4}$ \\
20 & Gravity direction & $3.67 \times 10^{-4}$ & $7.33 \times 10^{-4}$ & $3.67 \times 10^{-4}$ \\
40 & Gravity direction & $7.33 \times 10^{-4}$ & $3.66 \times 10^{-5}$ & $7.33 \times 10^{-4}$ \\
2 & Reverse gravity direction & $3.59 \times 10^{-5}$ & $8.82 \times 10^{-5}$ & $3.73 \times 10^{-5}$ \\
5 & Reverse gravity direction & $8.86 \times 10^{-5}$ & $1.47 \times 10^{-4}$ & $8.77 \times 10^{-5}$ \\
8 & Reverse gravity direction & $1.47 \times 10^{-4}$ & $1.83 \times 10^{-4}$ & $1.47 \times 10^{-4}$ \\
10 & Reverse gravity direction & $1.83 \times 10^{-4}$ & $3.67 \times 10^{-4}$ & $1.83 \times 10^{-4}$ \\
20 & Reverse gravity direction & $3.67 \times 10^{-4}$ & $7.33 \times 10^{-4}$ & $3.67 \times 10^{-4}$ \\
40 & Reverse gravity direction & $7.33 \times 10^{-4}$ & $7.33 \times 10^{-4}$ \\
\hline
\end{tabular}

It is generally considered that the dispersion coefficient $D$ is linearly related to the actual groundwater velocity $u$; that is, $D=\alpha u$, and $\alpha$ is the dispersivity. Due to the change of concentration and density in the variable density flow, the water head changes, that is, the groundwater flow is unsteady flow. Figure 7 shows that the velocity at each point varies with time in different directions of water injection.

When the dispersivity is calculated, the actual velocity is the average value of the velocity at the monitoring holes $\mathrm{A}$, $\mathrm{B}$, and $\mathrm{C}$ in the model, namely,

$$
\bar{u}=\frac{1}{N} \sum_{n=1}^{N} u_{i}^{n},
$$

where $u$ is the average value of the actual flow velocity, which is called the average actual flow velocity; $N$ is the total time; and $u_{i}^{n}$ is the actual velocity at the node $i$ and $n$ representing the $n$th time step.

The average actual velocities at the points of $\mathrm{A}, \mathrm{B}$, and $\mathrm{C}$ in each test are shown in Table 4 . It can be seen from Table 4 that the average actual velocity corresponding to different directions of water injection is different at the same flow rate. The relationship between the dispersion coefficient and average actual velocity at each monitoring hole in different directions of water injection is drawn in Figure 8. It is found that when the water injection rate is greater than $8 \mathrm{~mL} / \mathrm{min}$, the dispersion coefficient of the sand sample is linear with the average actual velocity, and the dispersivity is a fixed value. 


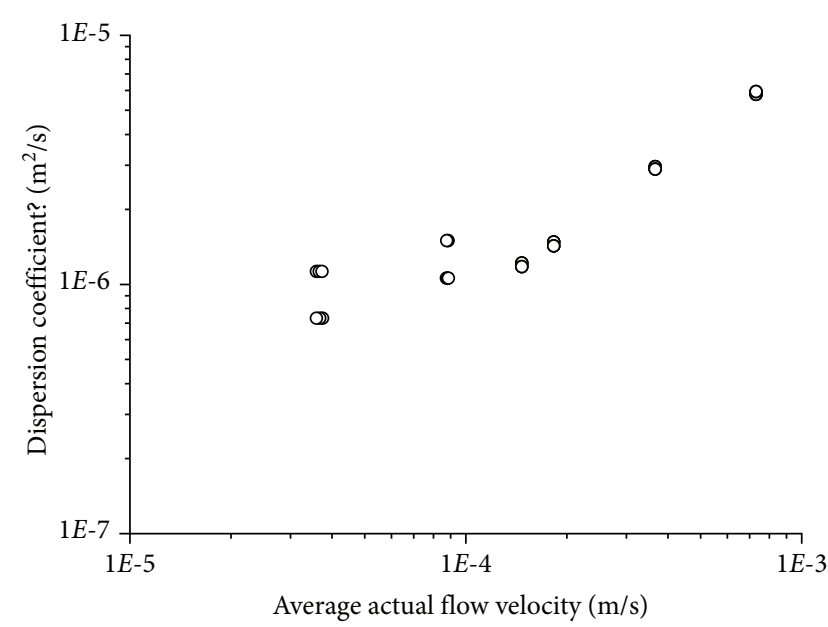

Figure 8: Diagram of relation between dispersion coefficient and average actual flow velocity.

When the water injection rate is less than $8 \mathrm{~mL} / \mathrm{min}$, the gradient of the curve slows down, and the dispersivity increases with the average actual flow velocity. When the flow velocity is small, the mechanical dispersion is weakened and the molecular diffusion becomes obvious, which makes the fitting value of dispersivity larger. The size of the sand sample is larger, and the particle size uniformity is better. The molecular diffusion is more obvious than the smaller particle size.

The dispersivity of each test is calculated using the average actual velocity at the monitoring hole $\mathrm{B}$. It is found that when the flow velocity is less than $8 \mathrm{~mL} / \mathrm{min}$, the dispersivity of the sand sample in the direction of reverse gravity is larger than that in the direction of gravity (Table 5). This is because when the water is injected in the direction of gravity, the freshwater is injected from top to bottom, and the large density of salt water hinders the flow of freshwater, which makes the hydrodynamic dispersion relatively weak. On the contrary, when the water is injected in the direction of reverse gravity, the freshwater is injected from bottom to top, and the heavier salt water is located on the lighter freshwater. At the same time, the salt water can promote the freshwater flow, intensify the hydrodynamic dispersion in the transitional zone, and make the dispersion larger. When the water injection rate is greater than $8 \mathrm{~mL} / \mathrm{min}$, the effect of variable density on the fluid is small, so that the dispersion of different water injection directions is close.

\section{Analysis of Different Vertical Flows of Variable Density Fluid}

5.1. Characteristics of Different Vertical Flows of Variable Density Fluid. In order to analyze the variation of variable density fluid with time in the model, when the velocity is $2 \mathrm{~mL} / \mathrm{min}$, the variations of density and velocity at each sampling point are calculated, respectively.

5.1.1. Density Variation. From Figure 9, one can see that the variation of density at each point is basically the same as that of the concentration variation. This is because the density of fluid depends mainly on the solute mass of the fluid, namely, the concentration of fluid, during the flow process of variable density fluid. The density variation of fluid affects the distribution of water head in the sand column, which leads to the change of variable density fluid.

5.1.2. Velocity Variation. The velocity of the model is $U_{0}$, when the model is stable. When the water is injected at different rates in different directions, the curve of velocity variation at the outlet is drawn as shown in Figure 10. The ratio of the real-time flow velocity to the steady flow velocity is taken as the longitudinal coordinate, and the dimensionless time is used as the transverse coordinate. It can be seen that there are different trends in the water velocity at the outlet for different water injection directions, and the curves in the two directions are basically horizontal symmetry. When the water is injected in the direction of gravity with the injection rate of $2 \mathrm{~mL} / \mathrm{min}$, the freshwater with low density is injected into the salt water with high density from up to down, and the high density fluid has a blocking effect on the flow of the low-density fluid. It makes the velocity decrease continuously, reaching its lowest value at the time of $0.4 T$. From Figure 9 one can see that the density at the outlet drops at the time of $0.4 T$, the blocking effect gradually decreases and the velocity rises. The velocity tends to be stable, when the density is reduced to be equal to the density of freshwater. When the water is injected in the direction of reverse gravity, the freshwater with low density is injected into the salt water with high density from the bottom to up. The high-density fluid promotes the flow of low-density fluid, which makes the velocity increase at this time, reaching its highest value at the time of $0.5 T$. The density at the outlet in the corresponding density curve begins to fall. The promotion effect gradually weakened, and the velocity began to decrease. When the density decreases to be equal to the density of freshwater, the velocity tends to be stable. The curve of velocity variation tends to be gentle as the increase of water injection rate. This is because the flow rate increases continuously, and the influence of the density difference on velocity is relatively small.

5.2. Optimization Model of Salt Water Restoration. In order to investigate the influence of the injection rate and time on the salt water restoration and find a method to optimize the efficiency of salt water restoration, the parameters related to the experimental model are used to calculate. The time and quantity of water used for restoring the salt water are calculated, by changing the water injection rate. Then, the efficiency of restoration of salt water is analyzed.

When the velocity is large, the dispersivity and average effective porosity are taken as the standard parameters to calculate the pumping efficiency in the model. Among them, the arithmetical mean of $\alpha$ is $0.77 \mathrm{~cm}$, and the variance of it is 0.05 . The arithmetical mean of $n_{e}$ is 0.46 , and the variance of it is 0.02 . In order to verify the reliability of the standard parameters of the model, the standard parameters are used to calculate. Then, the calculated values are compared with the observed ones. The error statistics are shown in Table 6.

It can be seen from Table 6 that the arithmetic mean value is used to calculate the model. The calculated results are well 
TABLE 5: Value of dispersion calculation for each group of tests.

\begin{tabular}{|c|c|c|c|c|c|}
\hline Direction of water injection & $\begin{array}{l}\text { Water injection } \\
\text { rate }(\mathrm{mL} / \mathrm{min})\end{array}$ & Dispersivity (m) & $\begin{array}{c}\text { Direction of } \\
\text { water injection }\end{array}$ & $\begin{array}{l}\text { Water injection } \\
\text { rate }(\mathrm{mL} / \mathrm{min})\end{array}$ & Dispersivity $(\mathrm{m})$ \\
\hline \multirow{6}{*}{ Gravity direction } & 2 & 0.0200 & \multirow{6}{*}{ Inverse gravity direction } & 2 & 0.0310 \\
\hline & 5 & 0.0120 & & 5 & 0.0170 \\
\hline & 8 & 0.0081 & & 8 & 0.0083 \\
\hline & 10 & 0.0078 & & 10 & 0.0081 \\
\hline & 20 & 0.0079 & & 20 & 0.0081 \\
\hline & 40 & 0.0081 & & 40 & 0.0079 \\
\hline
\end{tabular}

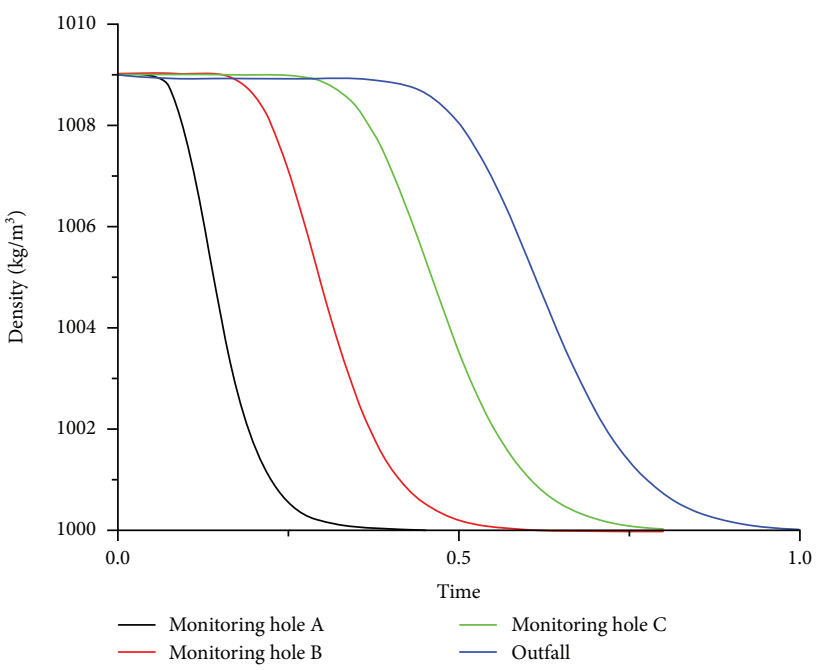

(a)

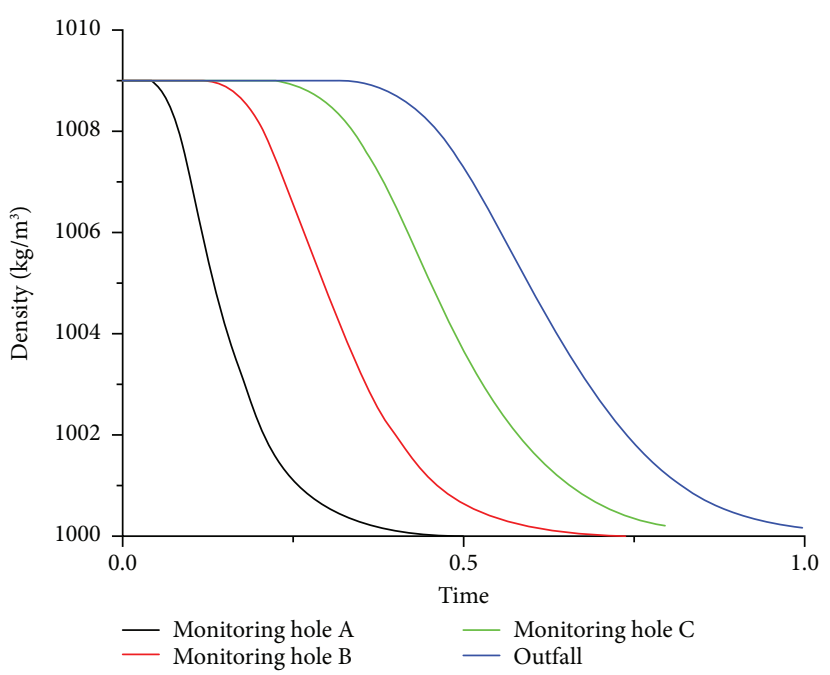

(b)

FIGURE 9: Comparison of density in different injection directions when the water injection rate is $2 \mathrm{~mL} / \mathrm{min}$ : (a) gravity direction and (b) reverse gravity direction.

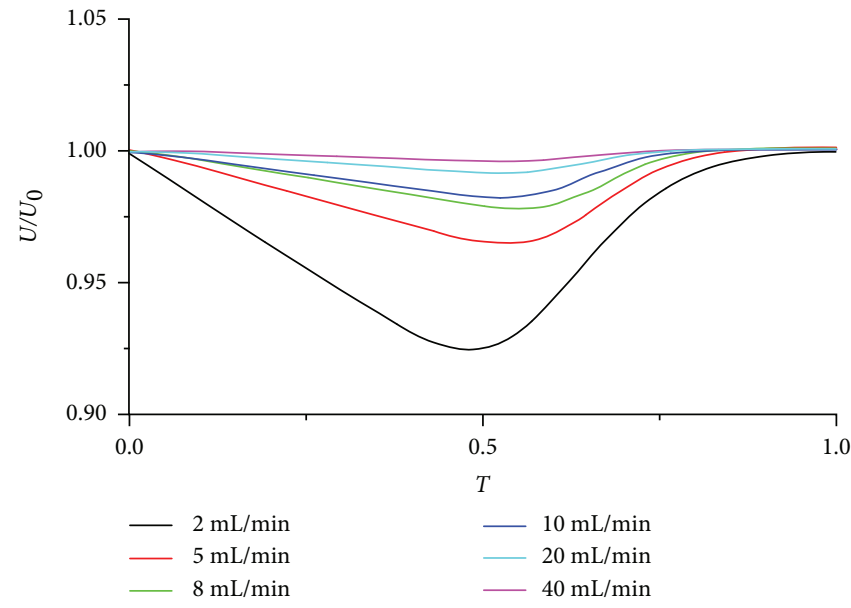

(a)

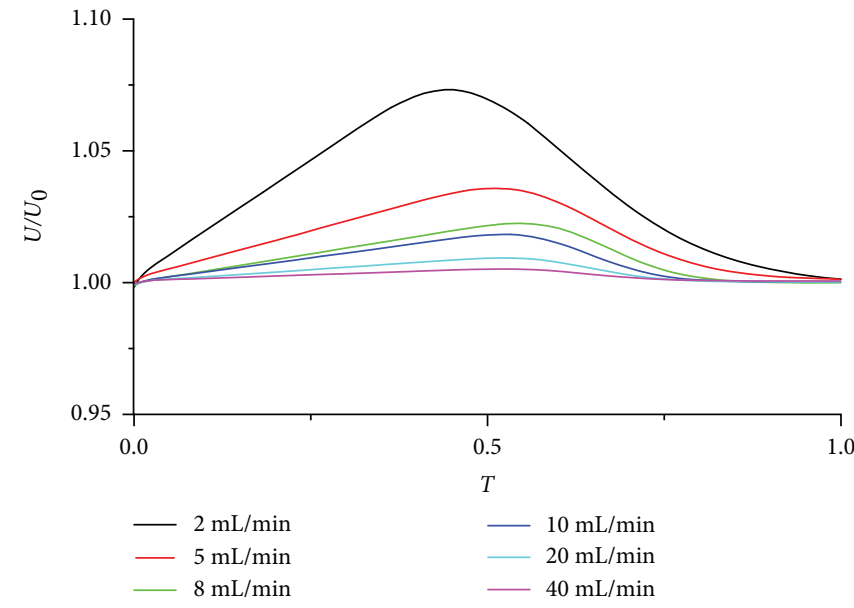

(b)

Figure 10: Comparison of flow rate at the outlet of each group test: (a) gravity direction and (b) reverse gravity direction.

fitted to the observed values, most of the standard deviations are below $1.5 \mathrm{~g} / \mathrm{L}$, and the maximum standard deviation is not more than $2.0 \mathrm{~g} / \mathrm{L}$. Therefore, the arithmetic mean value can be used to calculate the model. The standard parameters are used to calculate under the conditions of different water injection rates, and the results are shown in Figures 3 and 4.
As can be seen from Figure 11, when the mechanical dispersion is considered, the total amount of water used to repair the salt water increases with the increase of the water injection rate. This is because the mechanical dispersion induced by hydrodynamic action enhances as the increase of water injection rate, and the concentration exchange between the salt 
TABLE 6: Error analysis of standard parameters.

\begin{tabular}{|c|c|c|c|c|c|}
\hline $\begin{array}{l}\text { Water injection } \\
\text { rate }(\mathrm{mL} / \mathrm{min})\end{array}$ & $\begin{array}{c}\text { Direction of } \\
\text { water injection }\end{array}$ & Standard deviation $(\mathrm{g} / \mathrm{L})$ & $\begin{array}{l}\text { Water injection } \\
\text { rate }(\mathrm{mL} / \mathrm{min})\end{array}$ & $\begin{array}{c}\text { Direction of } \\
\text { water injection }\end{array}$ & Standard deviation $(\mathrm{g} / \mathrm{L})$ \\
\hline 8 & \multirow{4}{*}{$\begin{array}{l}\text { Along the direction } \\
\text { of gravity }\end{array}$} & 1.96 & 8 & \multirow{4}{*}{$\begin{array}{l}\text { Along the inverse } \\
\text { direction of gravity }\end{array}$} & 1.01 \\
\hline 10 & & 1.67 & 10 & & 1.14 \\
\hline 20 & & 0.92 & 20 & & 0.55 \\
\hline 40 & & 0.38 & 40 & & 0.30 \\
\hline
\end{tabular}

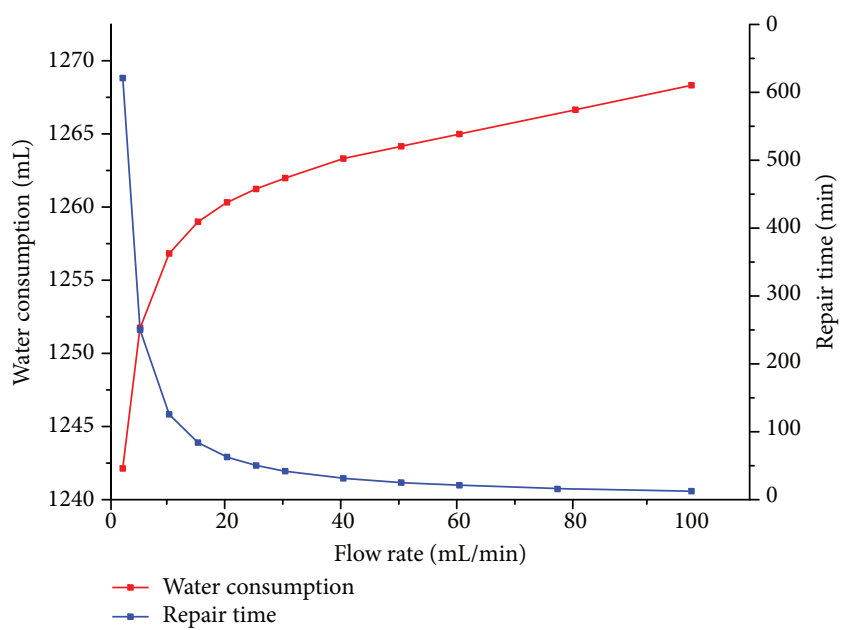

FIGURE 11: Simulation of repair time and water consumption with flow rate.

water and freshwater has been promoted. From the time perspective, the rate of freshwater propulsion increases with the increase of water injection rate, and the repair time reduces dramatically. However, when the velocity is small, the molecular diffusion is relatively prominent and cannot be ignored, and the dispersion value is affected by the scale effect. Therefore, the suitable time period and the zone of study area should be considered in the application. The selection of the appropriate rate of water injection can reduce the effect of mechanical dispersion and minimize the effect of molecular diffusion and maximize the efficiency of repair.

\section{Conclusions}

This study provides a new method for the restoration of salt water in the vertical direction. A one-dimensional mathematical model of variable density flow and solute transport is established. Using the laboratory experiments and numerical simulations, the effect of injection directions and injection rates of freshwater on the variable density flow was investigated. The main findings of the study are as follows:

(1) The density variation of fluid has the law of flow in the opposite directions. The test time in the gravity direction is shorter than that in the reverse gravity direction. The width of the transitional zone between the salt water and freshwater tends to be stable during the test. The width of the transitional zone changes a little with the water injection rate in each test. When the freshwater is injected in the reverse gravity direction, the width of the transitional zone between salt water and freshwater will increase with the decrease of water injection rate in each test. It shows that the free convection occurs between the upper salt water and the lower freshwater, when the water is injected in the direction of reverse gravity. Compared with the condition of injecting freshwater in the gravity direction, the hydrodynamic dispersion increases, and the influence of gravity on the solute transport cannot be neglected in the reverse gravity direction

(2) When the flow velocity is greater than $5 \mathrm{~mL} / \mathrm{min}$, the effect of variable density on the fluid flow is relatively small. The fitting dispersions in different injection directions are close. When the velocity is less than $5 \mathrm{~mL} / \mathrm{min}$, the fitting dispersion increases because of the obvious molecular diffusion effect. The fitting dispersion in the direction of reverse gravity is larger than that in the direction of gravity, due to the difference of the hydrodynamic dispersion effect caused by the variable density effect

(3) It is found that the variation of velocity is basically synchronous with that of density in the model by numerical calculation. When the water is injected in the reverse gravity direction, the freshwater with low density is located under the salt water with high density, and the salt water promotes the flow of freshwater and speeds up the flow velocity in the model. When the density decreases, the promotion effect is weakened and the velocity decreases. The variation of freshwater and salt water in the direction of gravity is opposite to that in the direction of reverse gravity. The change of flow and density interact with each other, which affects the transport of variable density fluid in the vertical direction

(4) The method of injecting freshwater into the aquifer is an effective method for restoring the salt water. The freshwater promotes the salt water transportation during the injection of freshwater. The faster the water injection rate is, the shorter the time it takes to repair it. Under the condition of the same water injection rate, the effect of injection of freshwater in the direction of reverse gravity is worse than that in the direction of gravity. The time for restoring the salt water increases significantly, and the total water consumption decreases with the decrease of the water injection rate. However, the effect of molecular 
diffusion cannot be ignored, when the water injection rate is small. Therefore, considering the suitable construction time and research area in the engineering application, a suitable water injection rate should be chosen, in order to improve the remediation efficiency and reduce the cost

This study considered the coastal aquifer, which was regarded as homogeneous. In field applications, the effect of heterogeneous aquifers, 3D effects, and the bottom boundary morphology should be considered. Additional experiments and modelling would be considered for a future work to the field practicability of this system.

\section{Appendix}

\section{Derivation of the Numerical Solution}

Based on equations (1)-(6), an implicit finite difference scheme is constructed. One can obtain

$$
\begin{aligned}
& -\frac{K \Delta t}{S_{S} \Delta z^{2}} H_{i+1}^{n+1}+\left(1+\frac{2 K \Delta t}{S_{S} \Delta z^{2}}\right) H_{i}^{n+1}-\frac{K \Delta t}{S_{S} \Delta z^{2}} H_{i-1}^{n+1} \\
& =H_{i}^{n}+\frac{\eta \Delta t}{S_{S} \Delta z}\left(C_{i+1}^{n}-C_{i}^{n}\right), \\
& -\frac{D \Delta t}{\Delta z^{2}} C_{i-1}^{n+1}+\left(1+\frac{2 D \Delta t}{\Delta z^{2}}-\frac{u_{i}^{n+1} \Delta t}{\Delta z}+\frac{\Delta t\left(u_{i+1}^{n+1}-u_{i}^{n+1}\right)}{\Delta z}\right) C_{i}^{n+1} \\
& -\left(\frac{D \Delta t}{\Delta z^{2}}-\frac{u_{i}^{n+1} \Delta t}{\Delta z}\right) C_{i+1}^{n+1}=C_{i}^{n}, \\
& u_{i}^{n}=-\frac{K H_{i+1}^{n}-H_{i}^{n}}{\Delta z} .
\end{aligned}
$$

When the injected water flows from up to down along the direction of gravity, the lower boundary is an unknown variable concentration boundary. The concentration of the lower boundary is assumed to be equal to the calculated concentration of its adjacent node. The conditions of the model are as follows:

$$
\left\{\begin{array}{l}
H_{i}(0)=H_{0}, \\
K \frac{H_{l}-H_{l-1}}{\Delta z}=q_{0}, \\
H_{1}(t)=H_{0}, \\
C_{i}(0)=C_{0}, \\
C_{l}(t)=0, \\
C_{1}(t)=C_{2}(t) .
\end{array}\right.
$$

When the injected water flows from down to up along the inverse direction of gravity, the concentration of the upper boundary is assumed to be equal to the calculated concentration of its adjacent node. The conditions of the model are as follows:

$$
\left\{\begin{array}{l}
H_{i}(0)=H_{0}, \\
-K \frac{H_{2}-H_{1}}{\Delta z}=q_{0}, \\
H_{l}(t)=H_{0}, \\
C_{i}(0)=C_{0}, \\
C_{1}(t)=0, \\
C_{l}(t)=C_{l-1}(t) .
\end{array}\right.
$$

\section{Data Availability}

All the data are in the figures of the paper.

\section{Conflicts of Interest}

The authors declare that there are no conflicts of interest regarding the publication of this paper.

\section{Authors' Contributions}

Zhifang Zhou and Qiaona Guo conceived and designed the study. Boran Zhang and Shumei Zhu analyzed the laboratory data. Zhifang Zhou wrote the paper with the assistance of Qiaona Guo.

\section{Acknowledgments}

This research was supported by the National Key R\&D Program of China (No. 2016YFC0402803) and the National Natural Science Foundation of China (No. 41772235).

\section{References}

[1] C. D. Langevin and W. X. Guo, "MODFLOW/MT3DMSbased simulation of variable-density ground water flow and transport," Ground Water, vol. 44, no. 3, pp. 339-351, 2006.

[2] C. T. Simmons, M. L. Pierini, and J. L. Hutson, "Laboratory investigation of variable-density flow and solute transport in unsaturated-saturated porous media," Transport in Porous Media, vol. 47, no. 2, pp. 215-244, 2002.

[3] Y. W. Chang, B. X. Hu, Z. X. Xu et al., "Numerical simulation of seawater intrusion to coastal aquifers and brine water/freshwater interaction in south coast of Laizhou Bay, China," Journal of Contaminant Hydrology, vol. 215, pp. 1-10, 2018.

[4] H. H. Qi, C. M. Ma, Z. K. He, X. J. Hu, and L. Gao, "Lithium and its isotopes as tracers of groundwater salinization: a study in the southern coastal plain of Laizhou Bay, China," Science of The Total Environment, vol. 650, Part 1, pp. 878-890, 2019.

[5] A. D. Werner, M. Bakker, V. E. A. Post et al., "Seawater intrusion processes, investigation and management: recent advances and future challenges," Advances in Water Resources, vol. 51, no. 1, pp. 3-26, 2013.

[6] X. K. Zeng, J. Dong, D. Wang et al., "Identifying key factors of the seawater intrusion model of Dagu river basin, Jiaozhou Bay," Environmental Research, vol. 165, pp. 425-430, 2018.

[7] J. Zhao, J. Lin, J. F. Wu, Y. Yang, and J. C. Wu, "Numerical modeling of seawater intrusion in Zhoushuizi district of Dalian City in northern China," Environmental Earth Sciences, vol. 75, no. 9, p. 805, 2016. 
[8] F. S. Ma, Z. H. Cai, and M. H. Yang, "Disaster of seawater intrusion and sustainable development strategy of regional agriculture," The Influence of Science on Society, vol. 4, pp. 32-38, 1998.

[9] Y. Q. Xue, J. C. Wu, C. H. Xie, and Y. X. Zhang, "Research of seawater and salt water intrusion of Laizhou Bay," Chinese Science Bulletin, vol. 11, no. 22, pp. 2360-2368, 1997.

[10] E. Abarca, E. Vazquez-Sune, J. Carrera, B. Capino, D. Gamez, and F. Batlle, "Optimal design of measures to correct seawater intrusion," Water Resources Research, vol. 42, no. 9, article W09415, 2006.

[11] B. S. Bray and W. W. G. Yeh, "Improving seawater barrier operation with simulation optimization in Southern California," Journal of Water Resources Planning and Management, vol. 134, no. 2, pp. 171-180, 2008.

[12] A. Vandenbohede, E. Van Houtte, and L. Lebbe, "Sustainable groundwater extraction in coastal areas: a Belgian example," Environmental Geology, vol. 57, no. 4, pp. 735-747, 2009.

[13] M. S. Sophiya and T. H. Syed, "Assessment of vulnerability to seawater intrusion and potential remediation measures for coastal aquifers: a case study from eastern India," Environment and Earth Science, vol. 70, no. 3, pp. 1197-1209, 2013.

[14] Y. Wei and X. L. Zheng, "In-site restoration test of saline aquifers at Dagu river watershed," Periodical of Ocean University of China, vol. 47, no. 1, pp. 26-31, 2017.

[15] A. Abdoulhalik, A. Ahmed, and G. A. Hamill, "A new physical barrier system for seawater intrusion control," Journal of Hydrology, vol. 549, pp. 416-427, 2017.

[16] M. Dejam and H. Hassanzadeh, "The role of natural fractures of finite double-porosity aquifers on diffusive leakage of brine during geological storage of CO2," International Journal of Greenhouse Gas Control, vol. 78, pp. 177-197, 2018.

[17] M. Dejam and H. Hassanzadeh, "Diffusive leakage of brine from aquifers during $\mathrm{CO}_{2}$ geological storage," Advances in Water Resources, vol. 111, pp. 36-57, 2018.

[18] W. Guo and C. D. Langevin, User's Guide to SEAWAT: A Computer Program for the Simulation of Three-Dimensional Variable Density Groundwater Flow, U.S. Geological Survey Techniques of Water Resources Investigations Book 6, Chapter A7, 2002.

[19] M. Goegebeur and V. R. N. Pauwels, "Improvement of the PEST parameter estimation algorithm through extended Kalman filtering," Journal of Hydrology, vol. 337, no. 3-4, pp. 436-451, 2007. 

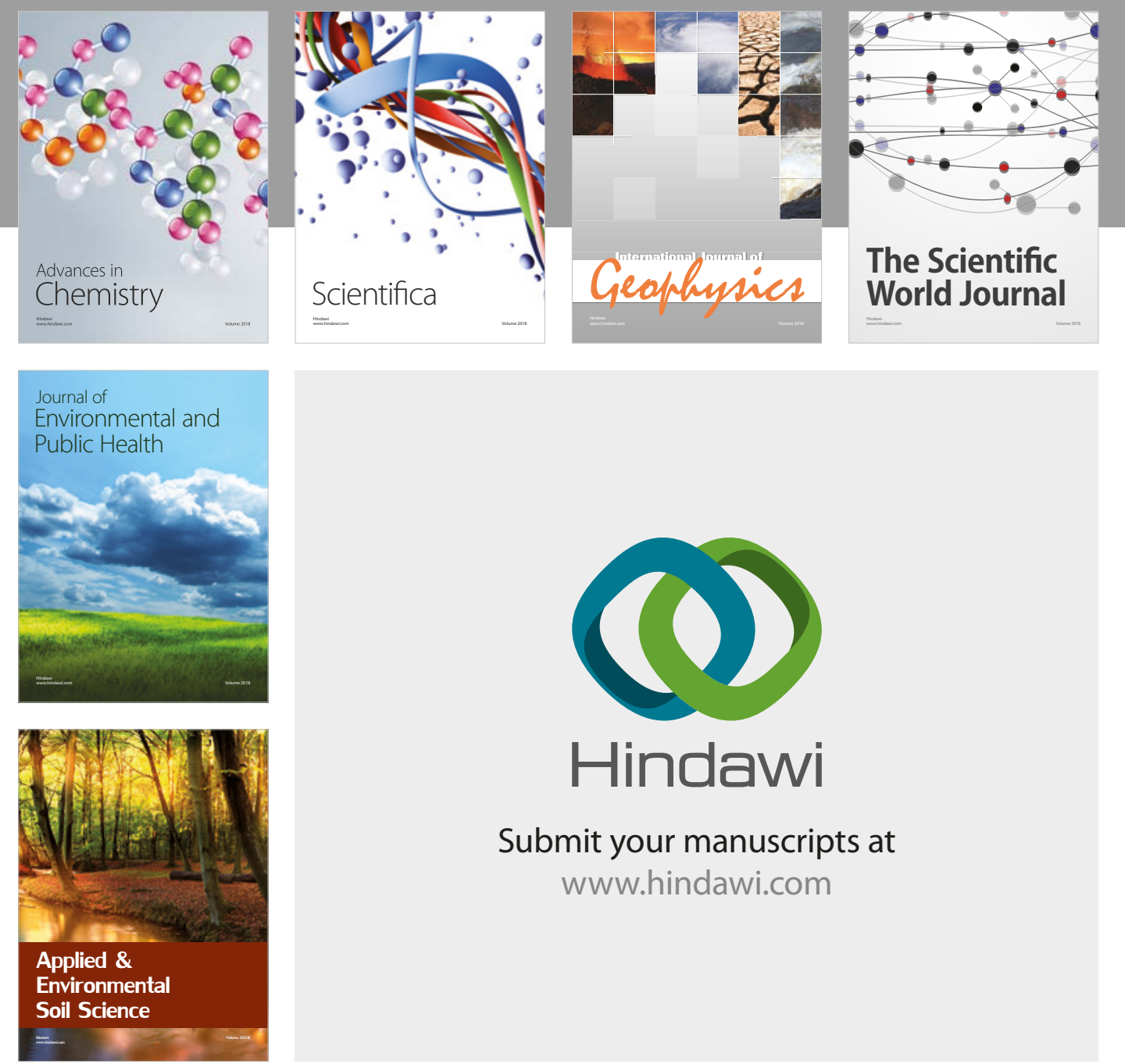

The Scientific

\section{World Journal}
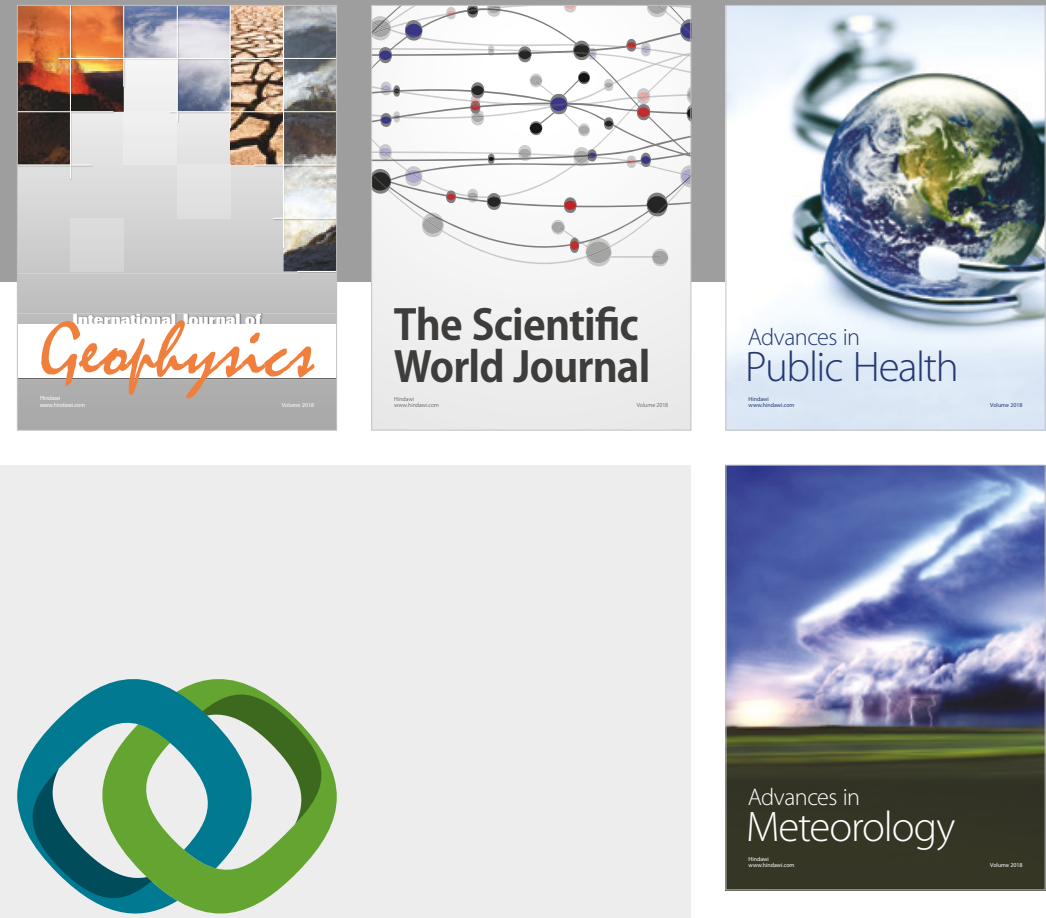

Advan

Public Health

\section{Hindawi}

Submit your manuscripts at

www.hindawi.com
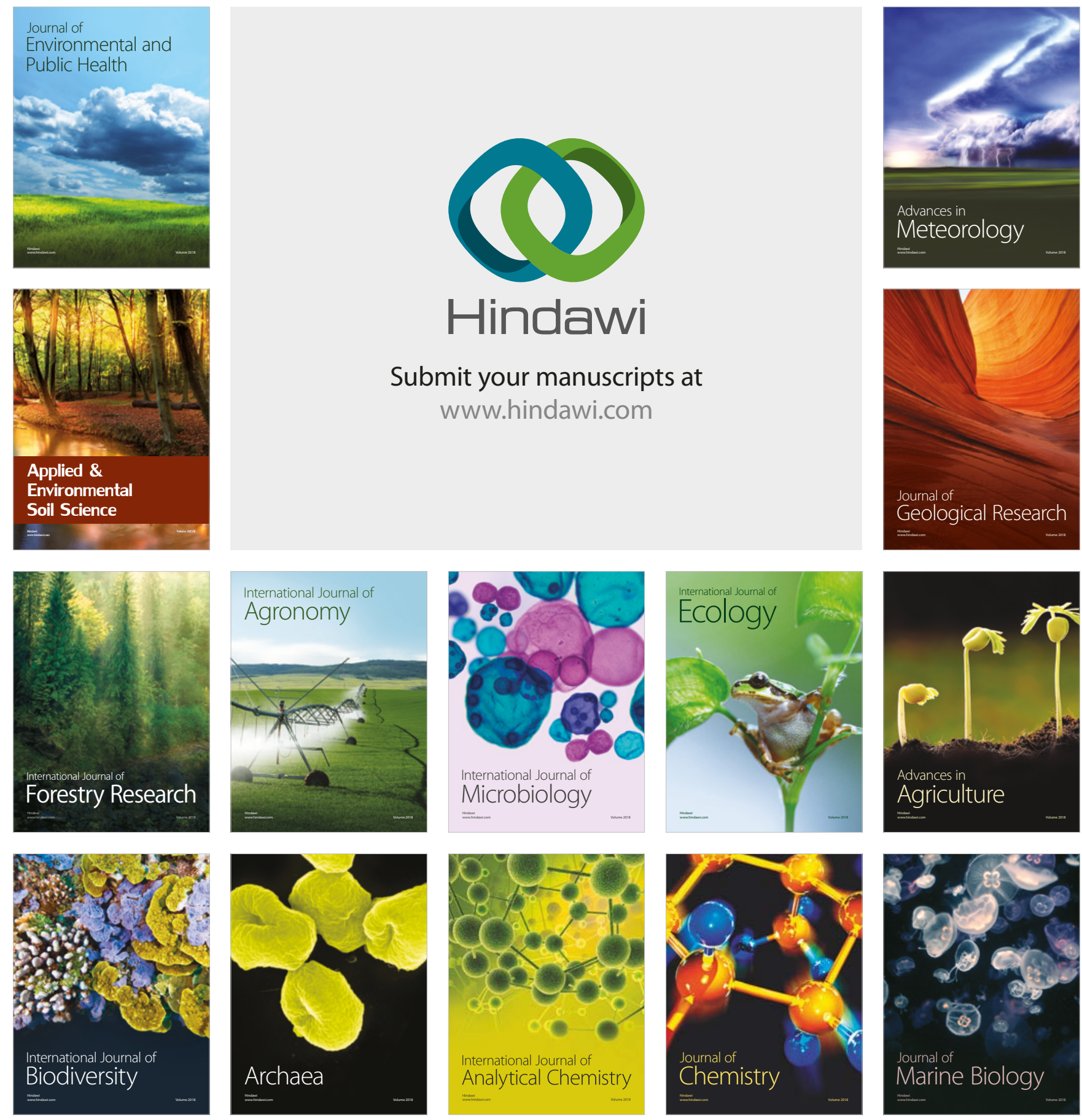